University of Redlands

\title{
Montessori Green School Initiative Mapping Project
}

\footnotetext{
A Major Individual Project submitted in partial satisfaction of the requirements for the degree of Master of Science in Geographic Information Systems

by

Wendy L. Wallace
}

Ruijin Ma, Ph.D., Committee Chair

Diana Stuart Sinton, Ph.D.

December 2010 


\section{Montessori Green School Initiative}

Mapping Project

Copyright (C) 2010

by

Wendy L. Wallace 
The report of Wendy Wallace is approved.

\section{Dana S. Sinton}

Diana Stuart Sinton, Ph.D.

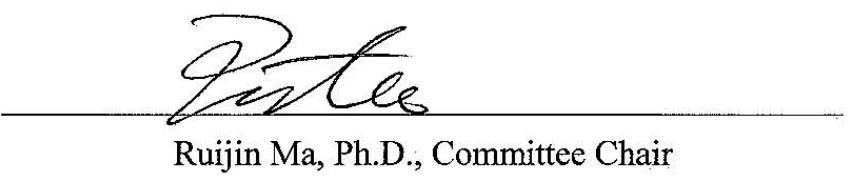

December 2010 



\section{Acknowledgements}

I would like to thank all of the people that helped me through this Masters of Science in GIS Program: Ruijin Ma, my advisor, Doug Flewelling, MS GIS Program Director, Debbie Riley, MS GIS Administrator, and all of the faculty and staff at the University of Redlands. Another huge thank you goes to the folks who proofread my chapters: Lynn Flewelling, Diana Sinton, Chris Rhodes, Tina Sides, as well as the writing tutors in the University of Redlands Library who helped me night and day through the last two years of this Masters Program. I would also like to thank my entire family, friends, and coworkers for encouraging me to persevere onto completing the program when times were tough. Thank you all, for without you, I could not have done this alone.

We do not inherit the earth from our ancestors, we borrow it from our children.

Native American Proverb 



\author{
Abstract \\ Montessori Green School Initiative Mapping Project \\ by \\ Wendy L. Wallace
}

The Montessori Green School Initiative Mapping Project, carried out for the Montessori School in Redlands, is one part of the Green School Initiative, which integrates efforts to reduce the school's ecological footprint, helps create a healthier school environment, and gets the community thinking about solutions to sustainability problems. This mapping project is important because it helps the students in visualizing concepts via maps, which is a good way to involve children early in map reading skills and environmental awareness. This helps perpetuate the ecological movement of saving the planet. The Montessori School's primary problem was the inability for the faculty, students, and parents to visualize the school's twenty-six acres of data geographically. The school needed help implementing the initiative strategically, so analysis was an important part of their conservation objective and in determining and implementing some of the key areas of the Montessori's Green School Initiative (GSI). The client required a system that combined environmental education with mapping and analysis techniques, while utilizing geographic information system (GIS) over the web. The categorized trees, campus, and usage data, as well as the carpool and "Safe Bike Bus" maps, supply their website with the information they need to help the environment. The resultant is the ability to edit the tree characteristics (category, type, size, health, diameter, and mineral deficiency), and the ability to update and analyze their utility and usage data over a web-based GIS system. 



\section{Table of Contents}

Chapter 1 - Introduction ................................................................................................ 1

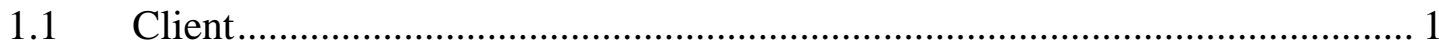

$1.2 \quad$ Problem Statement ................................................................................ 1

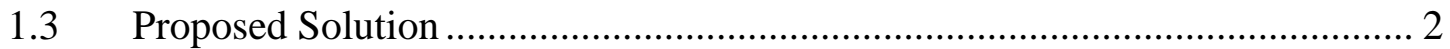

1.3.1 Goals and Objectives ............................................................................. 2

1.3.2 Scope

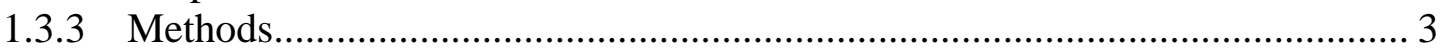

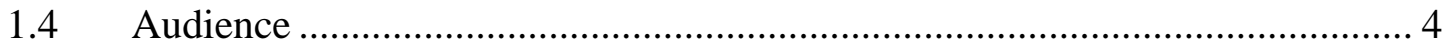

1.5 Overview of the Rest of this Report .......................................................... 4

Chapter 2 - Background and Literature Review ............................................................. 5

$2.1 \quad$ Teaching Green Principles................................................................... 5

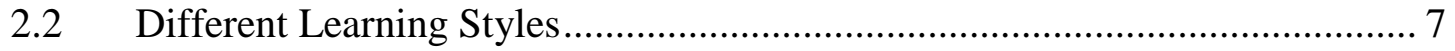

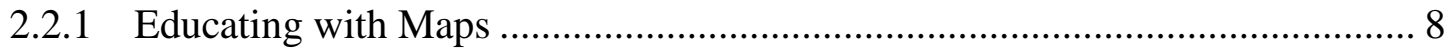

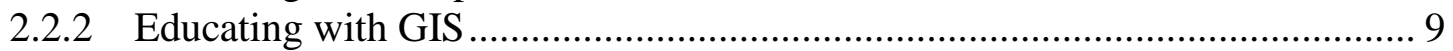

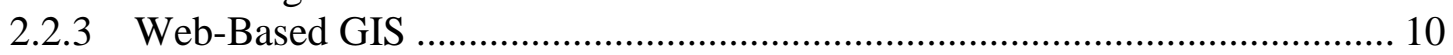

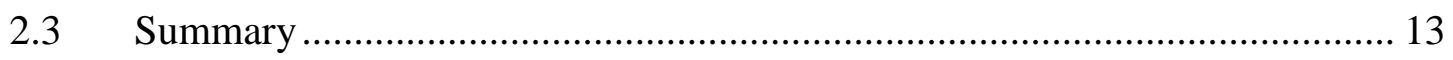

Chapter 3 - Systems Analysis and Design........................................................................ 15

$3.1 \quad$ Problem Statement ........................................................................... 15

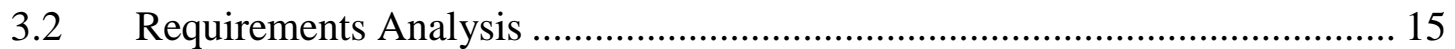

3.2.1 Functional Requirements ........................................................................ 16

3.2.2 Operational Requirements ....................................................................... 16

3.2.3 Technical Requirements.......................................................................... 17

3.2.4 Transitional Requirements ..................................................................... 17

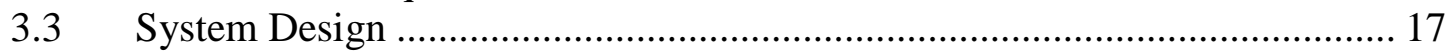

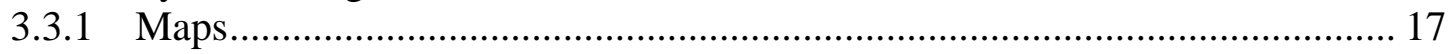

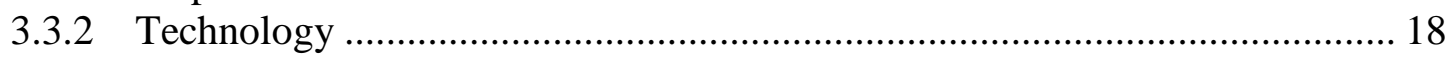

3.3.3 System Architecture ............................................................................... 18

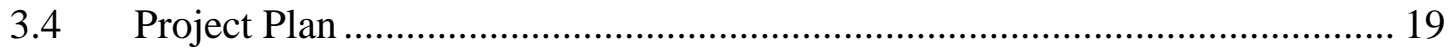

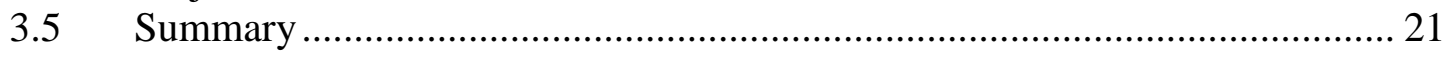

Chapter 4 - Database Design................................................................................................... 23

4.1 Conceptual Data Model ....................................................................... 23

4.2 Logical Data Model ............................................................................... 24

4.3 Data Collection Methods …………………………............................. 26

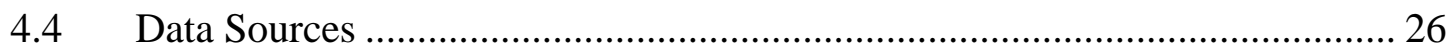

4.5 Data Refinement and Loading …………………..................................... 27

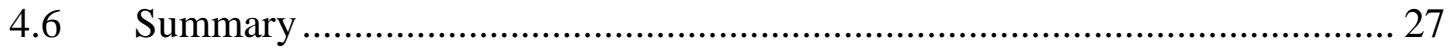

Chapter 5 - Implementation............................................................................................. 29

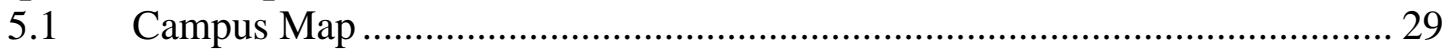

5.2 Tree Map Service .................................................................................. 30

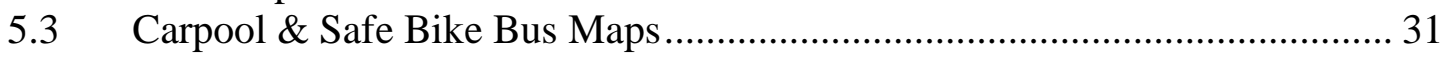

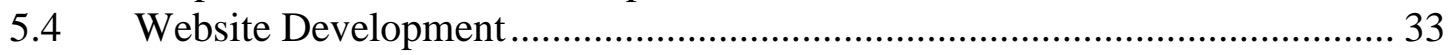

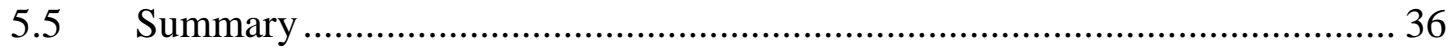


Chapter 6 - Results and Analysis........................................................................................... 37

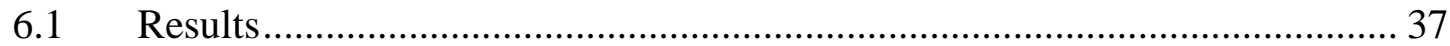

6.2 Analysis of the Problems Encountered ....................................................... 37

6.2.1 Campus and Tree Map Analysis ............................................................... 37

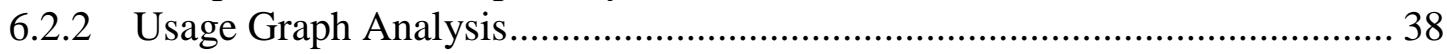

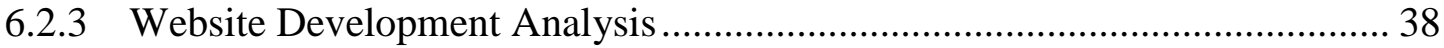

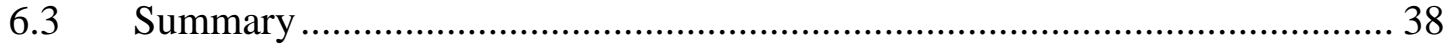

Chapter 7 - Conclusions and Future Work ............................................................... 41

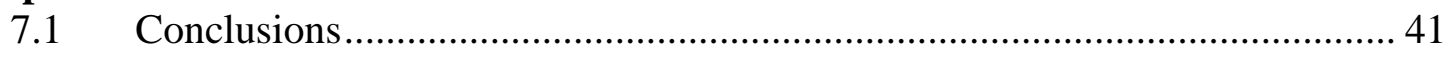

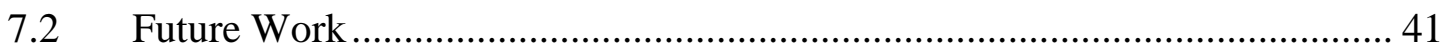

7.2.1 Biodiversity Project ................................................................................ 41

7.2.2 Mobile Application Project......................................................................... 42

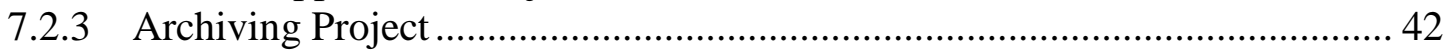

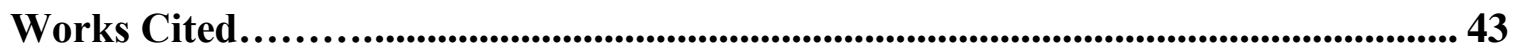




\section{Table of Figures}

Figure 1-1: $\quad$ Staged Methodology …........................................................... 4

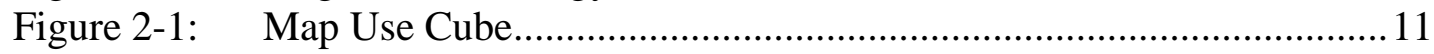

Figure 3-1: $\quad$ System Architecture .......................................................................... 19

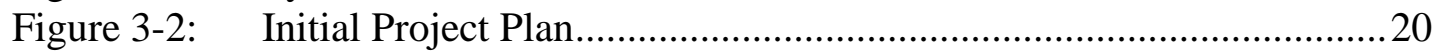

Figure 3-3: $\quad$ Updated Project Plan.................................................................. 21

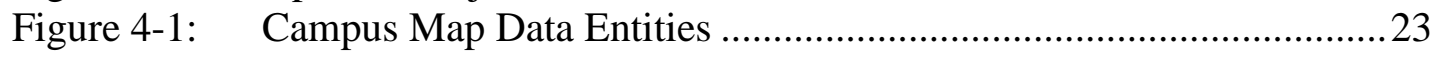

Figure 4-2: Carpool/Safe Bike Bus - Entity Attributes.........................................2 24

Figure 4-3: $\quad$ Campus Map Entities, Attributes, and Cardinality Rules ...................25

Figure 4-4: Carpool and Safe Bike Bus Entities and Attributes ..........................26

Figure 5-1: Utility and Usage Graph Attachments ..........................................29

Figure 5-2: $\quad$ Edit Capabilities of the Tree Map Service .......................................... 30

Figure 5-3: Dynamic Legends of the Campus and Tree Map Services ................ 31

Figure 5-4: Carpool Participants - Arrival Time Map ......................................... 32

Figure 5-5: $\quad$ Safe Bike Bus Participants and Bike Trails Map................................ 33

Figure 5-6: $\quad$ Enhanced Search Widget Tied to the Tree Map Service .................... 34

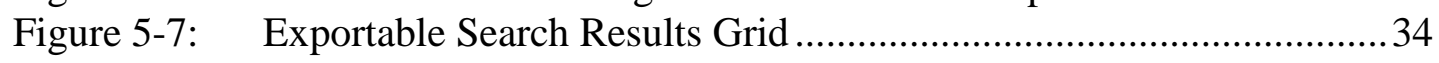

Figure 5-8: Drawing Capabilities from the Draw and Measure Widget................35

Figure 5-9: Measuring Capabilities from the Draw and Measure Widget ........... 35 


\section{List of Tables}

Table 1. Task Breakdown Structure ....................................................................... 3

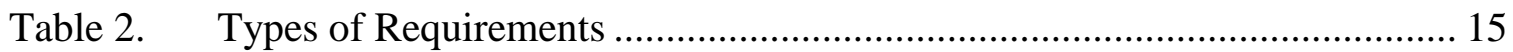




\section{List of Acronyms and Definitions}

$\begin{array}{ll}\text { ESRI } & \text { Environmental Systems Research Institute } \\ \text { FOSS } & \text { Free and Open Source Software } \\ \text { GDB } & \text { Geodatabase } \\ \text { GIS } & \text { Geographic Information System } \\ \text { GSI } & \text { Green School Initiative } \\ \text { IGIS } & \text { Internet Geographic Information System } \\ \text { IPD } & \text { Information Product Description } \\ \text { MIR } & \text { Montessori in Redlands } \\ \text { MS } & \text { Microsoft } \\ \text { OS } & \text { Operating System } \\ \text { RDBMS } & \text { Relational Database Management System } \\ \text { UI } & \text { User Interface } \\ \text { URL } & \text { Uniform Resource Locator } \\ \text { VM } & \text { Virtual Machine } \\ \text { WWW } & \text { World Wide Web }\end{array}$





\section{Chapter 1 - Introduction}

The Montessori in Redlands School requested assistance implementing their Green School Initiative (GSI) using a geographic information system (GIS). The United Nations Brundtland Commission definition of sustainable development states "development that meets the needs of the present, without compromising the ability of future generations to meet their own needs." (Murphy, 2008) This is the school's guiding principle for their Green School Initiative. The client identified ten key areas to focus on for their GSI: water, energy, citrus trees, buildings, greenhouse gases, biodiversity, waste, procurement, chemical use, and transportation. They utilize the term "levers" for each of these key areas, as they would like to prioritize, adjust the inputs, and monitor these levers' progress through time to see if the adjustments are effective. The school currently has ten student leaders, one for each lever. Each leader created a team of students to collect data to help study their individual lever, so they could help analyze which lever(s) to adjust. The best description that the students understood was "doing more good for the planet, while doing less harm." They wished to incorporate good processes (composting, recycling, and purchasing organic or recycled products), while minimizing the harmful processes (waste, greenhouse gas emissions, and toxic chemicals).

\subsection{Client}

The initial client for this proposal was Maura Joyce, Head of the Montessori in Redlands School. She expressed interest in implementing a system that would combine environmental actions with teaching the students mapping and analysis techniques utilizing GIS. Ed Murphy, Head of the Green School Initiative Team, became the technical liaison for this project and was the testing representative for the school. The staff and students collected baseline data for their facilities (buildings, sidewalks, pavement, and paths) and landscaping (trees, groundcover, and gardens), and compared it to satellite imagery. The client put together a GSI team consisting of the facility manager, faculty, students, and parents who are involved in this initiative. In general, the team had limited knowledge about GIS. They had some general requirements that would satisfy the needs of the Green School Initiative. They needed to determine the priorities of which levers to adjust for the greatest benefit for environmental and educational purposes. The students and staff needed to utilize an easy-to-use system without having to learn indepth GIS software. The client agreed to help generate requirements for this project after showing them what GIS could do for them.

\subsection{Problem Statement}

The Montessori in Redlands (MIR) School wished to become a greener campus by cutting costs, creating a healthier environment, and educating the children in environmental awareness. They proposed a Green School Initiative to study their current usage and waste in ten key areas. They wanted to determine which area they should focus on first by running "what if" scenarios of implementation costs vs. short and long-term savings. Prioritizing these levers is why the client wanted to analyze these scenarios 
utilizing GIS. MIR wanted the students, staff, and public to have the ability to analyze the data. The client needed help creating an easy-to-use system, as they did not have the time or capitol to invest in GIS training. The students did not have a means to enter the data they collected, nor a mechanism by which they could interpret the data. The faculty and staff did not have the ability to track progress, create new maps, analyze the data, or report findings.

\subsection{Proposed Solution}

To meet the goals of the Montessori Green School Initiative, this mapping project would give the staff and students the tools to analyze their data by utilizing a web-based GIS application. The system created would be easy-to-use, as the students ranged in age from four to seventeen years. The scope for this project narrowed down the levers that the students and staff could visualize and analyze in a geographic display. The methodology described below is the proposed solution to solve their problem.

The most important feature that the school needed was a campus map, which includes twelve acres of trees, buildings, recreational areas, and other campus facilities. The school also needed the ability to keep the tree characteristics up-to-date, so edit capability was critical for this project. The school gathered utility and usage data for the past two years and wanted to see them displayed on the website. The proposed greenhouse gas reduction ideas for this system included a carpool and "safe bike bus" (group of students riding bicycles together) application, where students and parents could find other students that live nearby or along their route to school with similar arrival and departure times.

\subsubsection{Goals and Objectives}

The goal of this project was to design and build a web-based GIS application for the Montessori in Redlands School that allows easy access to information about the school's resources regarding the levers that had a geographical association to their initiative. The system would help users learn basic capabilities of GIS, and develop analytical skills to manage their resources. Some specific school objectives included teaching students, parents, and staff green principles, as well as creating maps and reports of their campus data.

\subsubsection{Scope}

The scope was limited from the original ten levers to the following levers that had some kind of geographical ties: campus map that includes the trees, water usage, transportation, and building usage data (natural gas, electricity, and paper). This project required approximately 500 to 600 hours of work. Table 1 shows the initial breakdown for this GIS project: 
Table 1. Task Breakdown Structure

\begin{tabular}{|l|c|}
\hline Task & Time Duration (Hours) \\
\hline Analyze data and create geodatabase & 50 \\
\hline Import, clean, and re-project data collected & 40 \\
\hline Develop prototype screens & 30 \\
\hline Gather other necessary data & 40 \\
\hline Create easy to understand maps and symbology & 50 \\
\hline Application development & 120 \\
\hline Port to the web and test functionality & 80 \\
\hline Document the data (metadata), and the system & 100 \\
\hline $\begin{array}{l}\text { Training materials and system requirements } \\
\text { recommendation }\end{array}$ & 40 \\
\hline Total hours & $\mathbf{5 5 0}$ \\
\hline
\end{tabular}

Creating the maps, application development, and testing the web application was the most time consuming part of the project. Editing data over the web via the Flex Viewer is a new capability with ArcGIS 10. The project ran into many problems, such as the Flex Viewer changing three times, projections not matching up, editing templates not appearing on the web, as well as the edit widget not working at all. ArcGIS 10 SP1 came out in November 2010, which solved many of these and other problems encountered. The Montessori GSI website includes the following web capabilities:

1. Campus map with buildings, sidewalks, recreation areas, parking areas, etc. with the ability to draw different shapes to get distance, perimeter, and area

2. Editable tree attributes, and searchable by category, type, health, and size

3. Carpool map of participants willing to carpool together, categorized by arrival and departure times from school

4. Safe Bike Bus map of participants willing to ride their bikes together, categorized by arrival and departure times from school

5. Editable usage data and graphs for natural gas, electricity, water, and paper

\subsubsection{Methods}

ArcGIS 10.0 was the version that the system needed for editing over the web. Environmental Systems Research Institute (ESRI) agreed to provide the software for this Montessori Green School Initiative project, but the hardware for the system is not included, and the client does not have IT personnel to maintain the system. There are several options for hosting this system; the University of Redlands, City of Redlands, and ESRI have expressed interest in hosting the system free. The only item the client needs is an Internet Browser to access the system.

The Staged Methodology was useful for this project, since it is a combination of the waterfall and evolutionary methodologies. As sections of functionality were ready for client testing and approval, work could progress on the next section of functionality. Figure 1-1 shows the specific steps with client participation: 


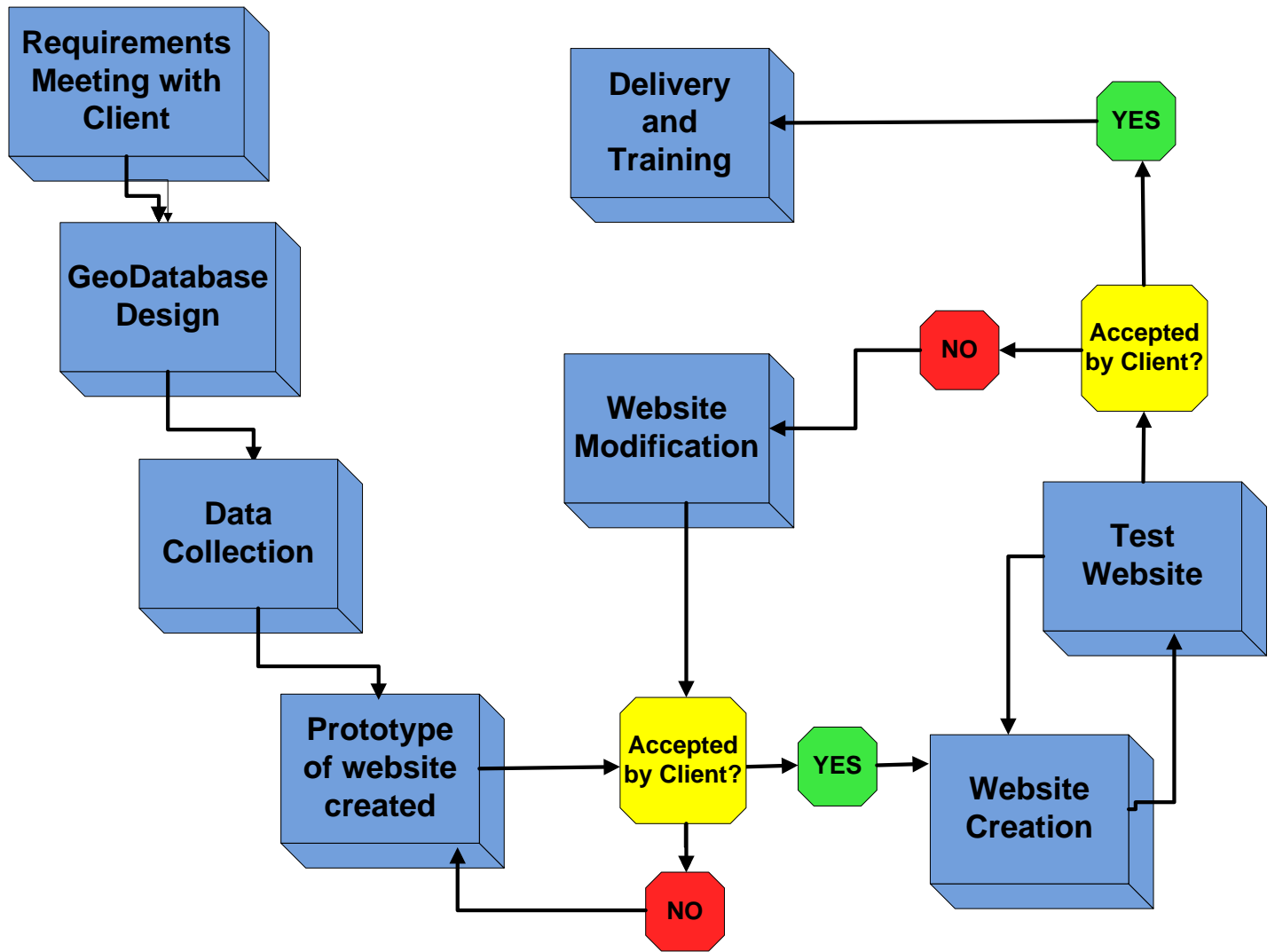

Figure 1-1: $\quad$ Staged Methodology

\subsection{Audience}

This project is for GIS and non-GIS professionals. The Montessori in Redlands staff and parents may or may not be GIS literate. Therefore, this document and the website are for the non-spatially-aware audience, in case other schools or organizations might like to implement similar projects.

\subsection{Overview of the Rest of this Report}

Chapter Two provides background literature relevant to the goals of this report. Chapter Three includes the Systems Analysis, from requirements gathering to the design of the system. The project scope and a plan to accomplish it show how it evolved over time. Chapter Four delves into the database design, data sources, and the preparation of the data. Chapter Five discusses the Implementation Plan, which describes procedures to deploy the proposed GIS solution successfully. Chapter Six provides the analysis and the results from the Green School Initiative Mapping Project. Chapter Seven has conclusions and detailed future work for the Montessori in Redlands School. 


\section{Chapter 2 - Background and Literature Review}

Several sources of information are available regarding the green revolution. Schools are teaching students to be more conscientious toward the environment. A few green school initiative websites exist on the web, with general topics of how to organize an initiative, data to be collected, and how to implement collaboration with other schools around the world. However, none of the existing Green School Initiative websites found utilized GIS as a learning tool for students. When reviewing research about how students learn, maps used in combination with text tend to help students with reading comprehension and memorizing facts and inferences (Wiegand, 2006), as well as understanding mathematical graphs and scientific tables (Sobel, 1998). Kerski declared there is a shortage of "readyto-go" packaged GIS software for the classroom, as "industrial-strength" GIS software may be too complex and time-consuming for students and teachers (2001). That is why this mapping project utilizes GIS in a web-based environment, offering a basic introduction of GIS functionality to students. Web-based maps are dynamic, interactive, and accessible to a wide selection of users as a visual communication and analysis tool (Dragicevic, 2004).

\subsection{Teaching Green Principles}

The concept of global warming is powerful, prevalent, and becoming an ever increasing threat to the very existence of the planet. The Earth consists of many biological and environmental events, each a cause or effect of others. To rescue the planet, everyone needs to get involved to find methods that link and solve the environmental problems together. For example, in order to solve water pollution one must look at air pollution, soil condition, animals living in or near-by, and sustainable energy at the same time (Johnson, 1995). Planning green activities, based on social and economic well-being, must manage our natural and physical environment in a sustainable fashion to continue to meet the current populations' needs and to allow future generations to meet their needs. In the past, scientists have usually only looked at one issue at a time, passing air pollution legislation one year, endangered species the next. This piecemeal approach has not worked well; everyone must look at the planet as a comprehensive whole and solve the problems in its entirety. GIS is such a tool we can use to analyze these biological and environmental chains simultaneously, by combining all possible sources of information that may or may not affect each other.

Humans produce approximately a kilogram of waste every day. In the past, people burned their waste in stoves; today it is stored in dumps or burned in incineration plants. Sixty-five percent of household waste ends up in dumps, which must be located on land that is naturally watertight, meaning clay or alluvial soil to avoid contamination of groundwater. Burning waste produces atmospheric pollution. Transportation leads to greenhouse gases, which heat up the planet. Carbon dioxide gas is not a pollutant itself, as it is essential in the process of photosynthesis. Plants retain the carbon and recycle the 
oxygen. What poses the problem is the imbalance of carbon dioxide production and consumption. Production results from phenomena such as the combustion of fossil fuels and volcanic activity. Consumption results from natural phenomena such as the absorption by oceans and from plants. It is not surprising that there is a surplus of carbon dioxide. Therefore, shifting our reliance from fossil fuel to non-fossil fuel energy sources, such as wind, water, and solar energy, produces cleaner energy for human consumption. (Poulit, 2007).

There is a lot of discussion regarding "The Greening of our Schools". Some schools are jumping in headfirst and seeing the need for change. Other schools are not quite there yet, waiting for things like funding, parent buy-in, and community support. Students, teachers, staff, and the planet are not as healthy as they could be. The fifty-five million students and more than six million adults in U.S. schools typically spend eighty-five to ninety percent of their time indoors, where the concentration of pollutants is as much as ten to one-hundred percent higher than outdoors. Children breathe, eat, and drink more per pound of body weight than adults, thus exposures of this magnitude at this age can disrupt normal development (Stone, M.K./ Center for Ecoliteracy, 2009).

The best place to start a wave of environmental change is in the schools. Teachers have the potential to create future generations of responsible citizens. At what age would it be appropriate for learning green principles? Connecting (or reconnecting) children with nature provides a win-win outcome for both children and the Earth. The world can change by supporting an environmental commitment at the individual and emotional levels, as well as at the community and cognitive levels (Holt, 2010).

Maria Montessori (the founder of the Montessori School System) recognized biological windows of time when certain kinds of learning automatically occur during sensitive periods, suggesting that the child is most sensitive to certain kinds of learning at different stages (Sobel, 1998). Montessori Schools take advantage of this theory by not pressuring students, as the students choose certain activities that interest them and are able to complete projects at their own individual pace. The Montessori in Redlands recognizes the need for students to learn not only green, but also GIS principles, so they created their own Green School Initiative to help set the standard.

Many schools have implemented similar green school initiatives with ecological and sustainable goals, yet none of the green school initiative websites found utilized GIS. GIS has many benefits, as it can provide a better visualization and help students realize the spatial contents in their life. GIS can also help with understanding mathematical principles and scientific formulas. For example, three websites of interest were GreenSchools.net, GoGreenInitiative.org, and ProjectGreenSchools.org. All three of these websites have a slightly different focus, yet schools can join in as a collaborative approach to solving and sharing ecological problems and solutions. Collaboration is a great tool for students as it offers a way for different locations to work together on a larger scale project to share insights that would not be possible working alone. It also promotes communication, encourages reflection, and provides a wealth of information to support student research.

The GreenSchools.net project emphasizes three major areas: 
- Health concerns: buying local/organic fruits, vegetables, green/toxic-free products, and avoiding pesticides, PVC, plastics, and lead

- Energy/climate concerns: carpooling/bicycling/walking to school, thermostat changes, composting food scraps, avoiding plastic bags and bottles, and using energy efficient light bulbs

- Economical concerns: recycling and using recycled materials (Moore, 2004)

The GoGreenInitiative.org project has a significant amount of information, as well as tools to help monitor progress for registered schools. The GoGreenInitiative.org website uses five principles that provide the framework for teaching environmentally responsible behaviors:

- Generate compost for fertilizing the garden; nature's way of recycling.

- Recycle everything that can be, and purchase recycled products.

- Educate students, teachers, and parents on environmentally responsible behaviors.

- Evaluate the environmental impact of every activity.

- Nationalize the principles of responsible paper consumption and use technology to communicate electronically as much as possible (Buck, 2002).

The ProjectGreenSchools.org project is to create healthier and greener learning environments in schools. By stating healthier and greener learning environments, they are looking at the individual's body as an environment, as well as the physical space of the school. They specifically address issues relating to:

- Indoor Air Quality

- Healthy Food and Habits/Nutrition

- The 3Rs: Reducing, Reusing, and Recycling

ProjectGreenSchools.org project aims to protect the health of every individual in their school and the planet by teaching people how to make more environmentally respectful and responsible decisions (Organ, 2008). These three websites all have great intentions in teaching students how to go about helping their schools and homes to becoming greener, but none of them utilize GIS to help the students and other users of the system to visualize their data geographically. GIS is a valuable tool for students in solving ecological problems in areas in which they live and areas in which they are familiar with. GIS gives them a sense of involvement and helps in collaboration projects with other students as well as other schools.

\subsection{Different Learning Styles}

Many topics present issues, concepts, or procedures that are at first complex and confusing to students. Simulations or electronic environments that allow students to interact with virtual events or locations can help make these concepts clearer and meaningful. Some simulations allow students to take an active part in historical situations that they would not otherwise be able to observe. Students often have problems 
visualizing abstract concepts such as timelines and maps. Teachers can use various technologies to represent these concepts graphically. Graphing software puts data into a concrete form for easier analysis and representation of concepts and allows geographic concepts to be portrayed easily (Roblyer, 2006).

Research suggests that students, given the opportunity to think about a local problem or concept, actively construct their own knowledge in order to experience conceptual change. This constructive approach produces high levels of student motivation and promotes the attainment of higher order thinking skills. Project-based learning is generally considered to be placed somewhere between inquiry and problem-based learning along an instructional learning scale (Purcell, Pomomarenko, \& Brown, 2006). Most products designed immerse students in problem-solving scenarios where they must make decisions and apply information they have learned. By placing students in the role of decision makers, students not only see the relevance in their daily lives, they also develop better problem-solving skills.

\subsubsection{Educating with Maps}

Spatial literacy is a fundamental skill and some consider it a key aspect of the learning process, yet many students have trouble with visualizing or translating between two, three, and four dimensions (time), as well as finding their location on a map when out in the field (King, 2006). Researchers suggest that young children do better constructing a map of their neighborhood using three dimensional blocks, cars, and trees, rather than drawing a two-dimensional map on paper. As a child's age increases, so does the scope of their maps. First graders draw pictures/maps of their schoolrooms and sandbox elements. Second graders draw maps of their school and playground. Third graders draw maps of their neighborhood and around their school. It is true that children can understand maps of greater sophistication than they can make, but one must maintain a developmentally appropriate mapmaking thread in the curriculum. Field trips also help children learn with maps. As their visible and accessible places increase, so does their mapmaking skills. Trips serve as a bridge to understanding maps of bigger places. Maps are a valuable connection between the real world and the abstract world, which can prepare children for understanding mathematical graphs and scientific tables. (Sobel, 1998).

The same is true for adults who have moved to a new city. Learning to navigate in a new city, one first identifies a few landmarks, such as home, school, and work. Then the newcomer learns the streets that allow travel between these locations. Exploring the surrounding areas, the newcomer gains knowledge of shortcuts and new routes based on an understanding of spatial relationships (Peuquet, 2002). The term geo-interpretation, defined as "interpretation that provides opportunities to experience geographic settings through the use of maps and other spatial representations" is a common term for map creators. Research in the fields of cartography, geography, and environmental psychology provide a hypothetical and experiential basis on which to base strategies for geointerpretation (Bailey, Smaldone, Elmes, \& Burns, 2007, pp. 45-59).

The use of internet mapping sites for locating places and planning routes is expanding rapidly alongside growing sales of conventional paper maps and atlases. That is why 
maps are very important for education. As a distinctive form of communication, "graphicacy" is a fundamental skill, along with reading, writing, and arithmetic. Graphicacy means the ability to produce or comprehend visual representations of information, such as drawings, creative collages, graphs, diagrams, and maps (Sobel, 1998).

Map-based activities are spreading to other parts of the school's curriculum. For example, science classes use computer-mapping tools just as much as, if not more than the geography classes. Many of the digital maps involving young people is community focused. Even though map popularity is on the rise, geography education has drifted away from maps as an educational tool. Evidence is stronger for children's thinking with large-scale maps of small places (such as a playground or room) than it is for their thinking with small scale-maps of the world. Students are able to make inferences about information when using a combination of map and text. It appears that students remember more map related facts from text if they have reviewed a thematic map before, rather than after, reading the text (Wiegand, 2006).

\subsubsection{Educating with GIS}

Paper maps are generally helpful for reference to find points of interest, routes, and so forth. Another kind of useful mapping is spatial analysis, where a user combines data as map layers needed for the problem at hand. Map layers include both vector-based maps and raster maps. Vector-based maps are composed of map layers having points, lines, and polygons. Raster maps are images that a GIS stores and retrieves for viewing within a geographic coordinate system, such as aerial photographs and satellite images. GIS is a computer-based, dynamic mapping system with integrated tools for storing, manipulating, visualizing, querying, and analyzing spatial data. Information systems are tools that provide answers to the questions who, what, when, where, why, and how. Until GIS came along, there was not a good way to answer the where question.

GIS links together commonly seen map features, such as bodies of water or county boundaries, with information such as pollution levels or population density, making it possible to see relationships that otherwise might not be apparent when viewing a static map. This technology is becoming a very popular way to help students visualize data distributed over geographic areas (Roblyer, 2006). While some teachers may fear that spatial analysis software like GIS may be too advanced for upper elementary students, ten and eleven-year old students have the spatial cognition abilities to understand map scale and directions (Allen, 2000).

Outside of schools, GIS is spreading fast in human activities. Although the number of people using GIS is growing, educators have not adopted the technology as hoped. GIS has diffused slowly in educational contexts worldwide. The introduction of GIS in education enhances students' understanding of the environment and sustainable ways of living. It also develops their digital literacy in geographical information, which is increasingly present in their daily lives, such as the personal navigation tools within mobile phones and car navigation systems. GIS requires and capitalizes upon higher order thinking skills. In order to foster such skills, teachers and students may need to 
work in new ways, such as enquiry-based methods and problem-based learning (Ludwig, 2000).

Kerski (2003) found that by the year 2000, only eight percent of the estimated 20,000 public and private high schools that have GIS software, only half of them were utilizing it. The reasons behind his findings were:

- Software was too complex for the teachers and the students

- Lack of time to develop a curriculum to include GIS activities

- Little technical and instructional support

- Hardware capacity to support GIS software

Nevertheless, educators believe that GIS technology has the power to transform education into innovative learning and teaching situations. GIS is a challenge to learn and use in the classroom, as the "industrial-strength" software is not adapted to classroom use. The learning curve is steep, and configuring ways to manage its use in learning is not self-evident to most teachers. Teachers express a willingness to learn software if they perceive that it will benefit their students and be well integrated into the curriculum (Bednarz \& van der Schee, Europe and the United States: The Implementation of GIS in Secondary Education in Two Contexts, 2006).

Introducing GIS at the elementary level reported to be highly motivating. However, it is also likely to cause frustration. Several promising approaches to the use of GIS in the elementary level suggested using local data in the context of an actual problem, developing elementary level GIS modules, and using a collaborative approach (Keiper, 1999). The data indicated that the students thrived on having the responsibility to make their own decisions and formulate their own strategies. A major concern of the elementary teacher was the need for a ready-to-use product. This was also a concern for secondary teachers as well (Palladino, 1994).

\subsubsection{Web-Based GIS}

The traditional model for a GIS assumes that the system consists of a single software package and data on a single machine. This model no longer meets the realities of most GIS projects. Large number of contributors may be involved, and there may be a large pool of potential users. They are likely to require the most current data available, not copies that may be months, or even years, old. A practical issue is how to provide widespread, device independent access to a GIS for a large number of contributors and users. The main difference between a web-based GIS and traditional systems is the separation of the user interface, data storage, and data processing. In web-based GIS, these elements are not required on one single machine, but spread across several machines.

There are many advantages and disadvantages of using GIS functionality in web browsers. Some of the advantages are that the system is potentially available to any user through a web browser, and implementing simple GIS functionality is quick and easy. Some disadvantages are that the system is limited to the specific functionality needed, interfaces need developing between the browser and the server, and many interactive 
processes become difficult to sustain in a distributed environment (Green \& Bossomaier, 2002).

With the internet, technology is now able to make GIS concepts more open, accessible, and mobile to everyone, thereby facilitating notions such as democratization of spatial data and effective dissemination (Dragicevic, 2004).

Web-based maps have two classifications: view-only maps and interactive contextual maps. Map use is critical in the design of web-based maps, as one must consider the user's needs up front. The "map use cube" in Figure 2-1 positions four goals of webbased maps, but there could be many more (MacEachren, 1994).

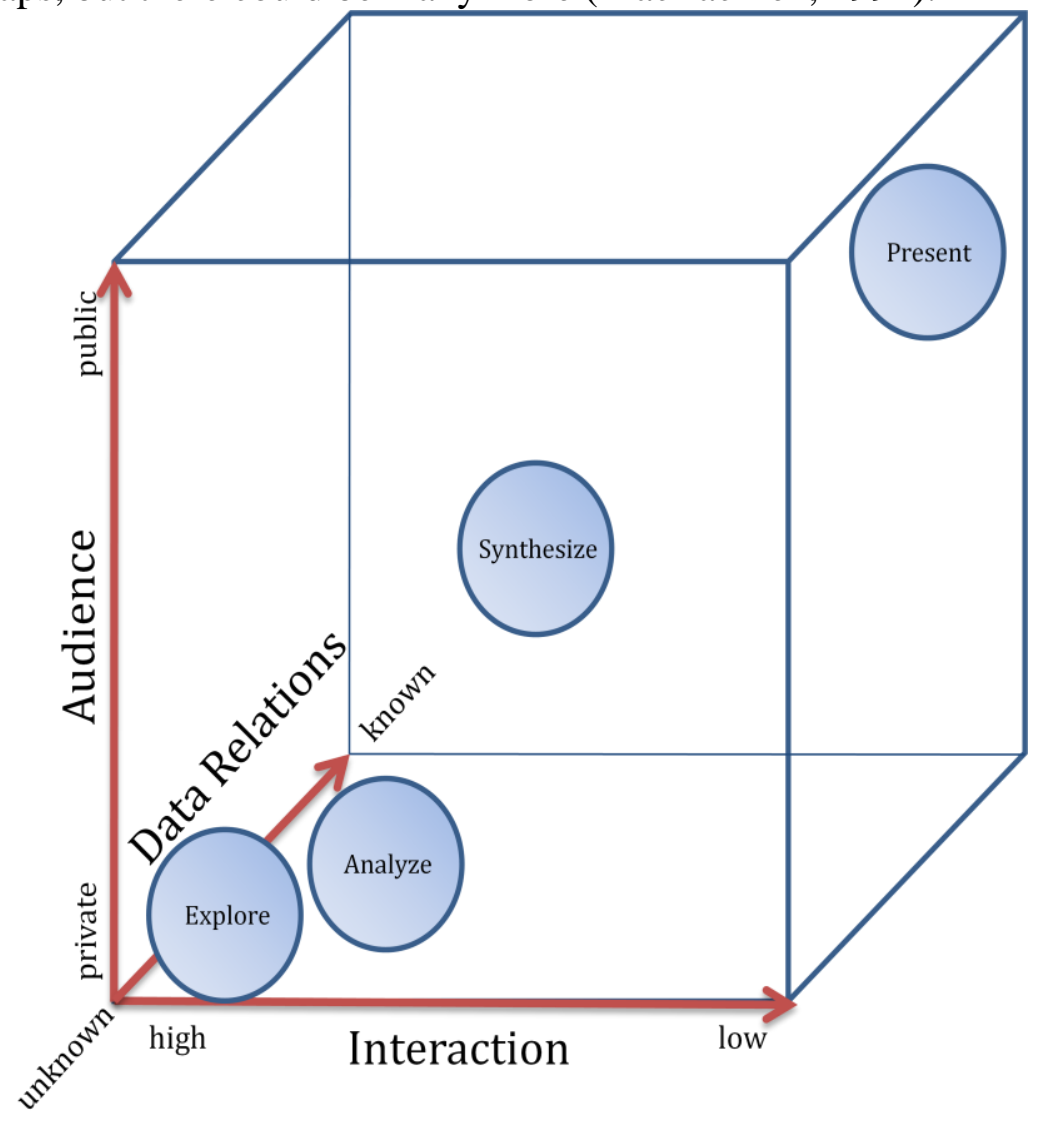

\section{Figure 2-1: Map Use Cube}

Maps may occupy any position in the three-dimensional space defined by the three axes. MacEachren recognized four map use goals: to explore, to analyze, to synthesize, and to present. Web maps can occupy other positions in the cube, depending on their use cases. In web cartography, as in cartography in general, many interesting developments take place in the bottom left corner of the map use cube. This is the position of exploratory cartography: map use in private, revealing the unknowns, and high humanmap interaction. Whereas the upper right corner of the map use cube is presenting known data relationships to the public, in this case via the internet.

The World Wide Web (WWW) has changed the perspective on the role that maps can play. Their traditional function remains, e.g. to represent a notion of a selected part of 
reality that offers an overview or insight into spatial patterns and relations. Maps can also function as an interface to other geographic and non-geographic information on the web. Maps can guide the user from point $A$ to $B$, because they represent concepts and selections of actuality. Maps play an important role in GIS, as they have the ability to integrate geospatial data from a wide variety of sources. The web allows one to offer data and maps independently and an unlimited number of users can access the map anywhere at all times (Kraak, 2004).

Teachers can access GIS-based lessons that support their curricula through internetbased GIS (IGIS), free education-oriented websites that employ GIS technology. Students taught through GIS-based instruction used websites as they completed the 5E (Engage, Explore, Explain, Elaborate, and Evaluate) learning cycle. Teachers evaluated the tested students' knowledge regarding the content before and after the GIS exercises, as well as students using traditional learning methods without GIS. The GIS students performed better than the non-GIS students did on the post-test when a map component was involved. The majority of students surveyed enjoyed using GIS, thought it was easy to use, and would like to use it again. This finding is important because it addresses students' positive interest in using IGIS and that it can be a powerful tool to assist teachers in engaging students in scientific learning.

Collaboration using email and internet-based projects offers a way for students in different locations to work together to share perspectives and gain insights that would not be possible working alone. As students collaborate to study a problem, these projects tend to promote communication, encourage reflection, and provide a wealth of information to support student research (Roblyer, 2006).

Several emerging IGIS environments exist, such as the National Atlas (2006), American FactFinder (United States Census Bureau, 2010), and Globalis (An Interactive World Map, 2006). All of these web-based GIS sites provide a promising alternative to desktop GIS in educational settings due to free access, familiar interfaces, and large, upto-date databases (Baker, 2005), (Milson, 2006). Users access an IGIS through a web browser where geographic data displays maps and graphs based on user-selected criteria. The typical IGIS interface includes common GIS tools such as pan, zoom, identify, and select. Many IGIS also provide navigational tools such as drop-down menus, check boxes, and buttons to aid a user in manipulating the data. Often, a user has the ability to save, print, and email the maps he or she creates. Given the IGIS delivery method as a web browser, the tools and graphic interface of most IGIS are more familiar and forgiving than the typical desktop GIS (Purcell, Pomomarenko, \& Brown, 2006).

In 1998, then-Vice President Al Gore articulated Digital Earth, and Google Earth and Google Maps launched in 2005 (Hanke, 2007). NASA's World Wind and ESRI's ArcGIS Explorer are examples of open source software and designed for scientific data. Free and Open Source Software (FOSS) is a major component for IGIS. This FOSS trend includes freedom to run the program for any purpose, to study and modify the program, and to redistribute copies or modified versions of the program. FOSS cartography has taken a number of forms, with self-made map mashups. Google introduced "My Maps" in 2007, while Microsoft has "Collections." These mashups become somewhat easy to make, share, and imbed on websites. OpenStreetMap's (OSM) goal is to provide free global geographic data such as roads, streets, railways, and so on to the public. OSM collects 
data from members that drive, bicycle, or train around the country with GPS units, and upload their waypoints into OSM's map, avoiding the purchase of licensed data from NAVTEQ and Tele Atlas, unlike Google and Microsoft. An interesting cartographic application of Wikipedia is Wikimapia. Over four million entries entered from Wikipedia places and inserted into Wikimapia, but users can add their own places as well. Microsoft's Photosynth ${ }^{\odot}$ technology integrates visual data, such as photographs from cell phones and digital cameras, and stitches them together geographically (Crampton, 2009). This collaboration phenomenon over the web is spreading, as people enjoy participating and in helping others.

One of the strong points of the WWW is the fact that it is virtually platform independent. The data runs on just about any operating system (OS), and web browsers are available for every type of computer used for retrieving and viewing data over the internet. To publish maps on the web, one needs very few resources:

- A connection to the internet, with a fixed and high capacity transfer rate

- One or more computers using the above internet connection

- An application that understands http protocol: listens for requests and responds by transmitting the information requested.

- Basic html editor to author html files

- Graphics software tools for web graphic design (Purcell, Pomomarenko, \& Brown, 2006).

IGIS provides "a unique and powerful tool for extending K-12 standards-based inquiry, while simultaneously avoiding the traditional barriers of desktop GIS implementation." (Baker, 2005, pp. 44-50) Baker defined two forms of IGIS that he labeled Atlas-style Web maps and Collaborative Web maps. An atlas-style IGIS provides the user with access to a large database of real-time and archived geographical data through an interactive interface. The purpose of the atlas-style IGIS remains similar to a traditional atlas; namely, information retrieval and visualization of a broad range of features. On the other hand, collaborative IGIS focuses on particular topics and offer greater opportunities for participation and collaboration across distances.

\subsection{Summary}

Reported probable barriers to widespread implementation of GIS in K-12 settings include:

- the lack of teacher preparation in GIS

- the complexity of GIS software designed for professional use

- teachers' limited time for GIS curriculum development

- the lack of standards for GIS in education

- the limitations of school technology infrastructures

- technology anxiety among teachers, and

- institutional pressures on K-12 teachers to focus on standardized test objectives and content-transmission pedagogies (Baker, 2005), (Bednarz \& Audet, The Status of GIS Technology in Teacher Preparation Programs, 1999), (Gatrell, 2001), (Kerski J. J., 2003), (Milson, 2005), (NRC, 2006). 
IGIS can be a successful tool for geographic education in an inductive learning environment. Students are able to access and make use of geospatial data. Neither the students nor the teacher require extensive training in how to use the technology in order to accomplish their learning goals. The familiar web browser interface allows students to search for ideas, identify issues, and select maps and graphs that tell the story without a time-consuming introduction to software. The students' perception of enhanced freedom using IGIS served as an important motivating factor leading to greater student engagement. IGIS can help eliminate many of the barriers that have prevented widespread adoption of desktop GIS. Maps have a definite role to play in an IGIS environment. As long as the website has an interactive and dynamic appearance, it will guide and assist the user in solving geospatial analysis problems. IGIS are exploratory tools that stimulate visual thinking anywhere and at any time (Kraak, 2004). 


\section{Chapter 3 - Systems Analysis and Design}

The Montessori in Redlands (MIR) School wished to become a greener campus by cutting costs, saving the environment, and educating the children in social awareness. They proposed a Green School Initiative to study their current usage and waste in ten key areas. There were many Green School Initiative (GSI) meetings held at the school, which parents, staff, and the head of the school and head of the GSI attended and brainstormed different ideas to help the initiative. One-on-one meetings with the heads of the School and Green School Initiative helped gather detailed requirements and to see what they were currently using for their campus maps, all of which were on paper. The user's needs resulted in the Information Product Descriptions (IPD's).

\subsection{Problem Statement}

The Montessori School needed to determine which area they should focus on first by running "what if" scenarios utilizing GIS. MIR wanted the students, staff, and public to have the ability to analyze the data and monitor the progress. The client needed help creating an easy-to-use system, as they did not have the time or capitol to invest in GIS training. The students and staff did not have a means to enter the data collected, interpret the data, track the GSI progress, create new data, create their own maps, or report their findings.

\subsection{Requirements Analysis}

One must address and analyze several types of requirements before creating a GIS web application. Table 2 summarizes the different types of requirements that were determined for this project. The descriptions of each type of requirement are in following sections.

Table 2. Types of Requirements

\begin{tabular}{|l|l|l|l|}
\hline Functional & Operational & Technical & Transitional \\
\hline User Needs & Updates to the Data & Technology Constraints & Data Conversion \\
System Needs & Database Backups & User Interface & Documentation \\
& Version Handling & Reports & Testing \\
& Archiving & Navigation & Training \\
& & Error Handling & Deployment \\
& & & \\
\hline
\end{tabular}




\subsubsection{Functional Requirements}

The functional requirements are to support the many users for this Montessori Mapping Project, namely the three hundred students, their parents, and the Montessori staff, which includes the Facilities Manager. They all have different needs, but if the system is designed correctly and is intended for the students' ease of use, the parents and staff will be able to utilize it as well. The main functions of this Mapping Project are to have the ability to query, visualize the information asked for, and print out their results if the user wishes to. The three main applications the client has requested are:

- to visualize, query, and update the twelve acres of tree inventory data

- to find others who would like to carpool or ride in the "Safe Bike Bus" (students bicycling together in a group) to and from school

- to analyze their usage statistics (electricity, gas, water, and paper) over time

The needs of the system are to have at least one Windows machine to run on. The Web Server might reside on the same server as ESRI's ArcGIS Server and Microsoft SQL Server Express, which houses the geodatabase (GDB). The maintenance of the database backups, versions, and upgrades to the ArcGIS software, which created the website's maps, is up to whoever hosts their system; the current plan is for University of Redlands to host it for the first year free. The implementation section has detailed instructions for maintenance considerations. The web application needs a URL for the website so the client can access the system. Since the system will be accessible via a website, the users need access to the internet via a web browser, such as Mozilla Firefox, Internet Explorer, Google Chrome, etc. There are no data interfaces or data exchange requirements for this project, as the data needed is self-contained in one geodatabase.

\subsubsection{Operational Requirements}

The main operational requirement for the Montessori Mapping Project is the need to keep their twelve-acre tree inventory current via a web browser, as they do not have access to ArcGIS Desktop for editing. They need the ability to update the tree type, health, and size of each tree, as well as to add new trees to the map. This required extra security, so a separate URL and edit version, created just for live edits, made sure that only certain people have access to update the data. The URL for all users points to the read-only edit version in ArcSDE, so everyone will see the latest data. A test version, created for testing, is for training and can be used as a playground for the students and others to edit features. The original data is also stored in the default version, which can be reconciled and posted with the edit version at any time, but requires ArcGIS Desktop access. The usage data will also need an edit interface to create new month-end usage data for electricity, natural gas, water, and paper. This way they can see the trends of how their Green School Initiative is helping to reduce their ecological footprint.

Backup of the database needs to happen regularly and tested occasionally for machine failure and disaster recovery purposes. The timing of these activities is based on how often the data changes. Daily changes might require daily backups and monthly testing, whereas monthly updates might require monthly backups and quarterly testing. 


\subsubsection{Technical Requirements}

The technical requirements of this Mapping Project were to design and build a userfriendly, web-based GIS interface geared toward the students, so that all of the users, including the Montessori staff and parents, can navigate through the system with ease. The system is captivating and interactive for the students, as well as functional and straightforward to ensure the users understand the data displayed. The typical navigation interface is incorporated (plus sign to zoom in, minus sign to zoom out, hand symbol to move the map). These GIS applications include a visualization of their twelve-acre campus and the surrounding area with an interface to analyze data, create and print maps.

The programming environment for the web interface is ESRI's ArcGIS Viewer for Flex, which connects ArcGIS Server .NET, Microsoft's IIS Web Server, and the endusers web browser. The system, designed on Microsoft Windows 764 bit server, uses Microsoft SQL Server Express 2008, and ArcGIS Server .NET 10.0 for the updating and time sequencing functionality.

\subsubsection{Transitional Requirements}

The transitional requirements have to do with the delivery of data from the client to the developer, as well as the completed system from the developer to the client. The symbols for the trees were multi-level complex symbols. Trees categorized by type symbolized on the web reflect the GDB domain.

The testing efforts include the developer, friends, and the Montessori staff. Testing commenced only after it had made it through internal comprehensive web testing efforts by the developer. A GSI meeting occurs every few months, so a training session could take place during one of the meetings to train the GSI team, and another meeting for interested parents and students. The client has chosen the University of Redlands to provide complimentary hosting for one year. There is also the possibility of transferring this system to the City of Redlands as they have agreed to host it for free as well.

\subsection{System Design}

The user's needs and Information Products Descriptions led to defining the following system design, which focuses on the maps, technology, and system architecture.

\subsubsection{Maps}

The design of the maps was important, as it affects the speed and accuracy of the system. The most important consideration of designing a well-performing web mapping application was determining the operational layer maps vs. basemaps. Since the tree, transportation, and utility data need updating, they must be part of the operational layers, which are dynamic so that their updates will appear right away. The basemaps help orient the user to the surrounding areas. They include the campus map, satellite imagery, shaded relief, and topological maps, cached for faster access. Over time, the basemaps generally do not change, if they do, then the cached tiles need to be updated. Since most of the basemaps are coming from ESRI's ArcGIS Online, they are responsible for the updates. 
The operational maps will also need to match the map scales defined in the basemap cache, so the level of detail is the same. There are other considerations to speed up the map rendering over the internet, like symbology, labeling, and creating an optimized map service definition.

\subsubsection{Technology}

The main objective for this web-mapping project was to design and build a user-friendly, web-based GIS interface, geared toward the students, so that all of the users can navigate through the system with ease. The system must be captivating and interactive for the students, as well as functional and straightforward to ensure the users understand the data displayed. The technology chosen must have the typical mapping interfaces. This webmapping GIS application has an interface to toggle layers on and off to query and analyze the data. The system will also have a choice between basemaps: satellite imagery, shaded relief, or topology information in the background for user reference.

The programming environment for the web interface are the ArcGIS Flex Viewer, Flex 2.0 API, which will connect to ArcGIS Server .NET 10.0, an IIS Web Server, ArcGIS Online basemaps, and the end-users internet browser. The original system was developed using ArcGIS Desktop and Server .NET 9.3.1 and was ported to ArcGIS 10.0 for the Flex edit capabilities and time sequencing functionality. The client initially requested a Linux OS, as they do not have funding for the Operating System (OS) or a Relational Database Management System (RDBMS). Therefore, they wanted a Linux OS, and either a File geodatabase (GDB) or PostGresSQL GDB, based on no cost. Editing with the Flex Viewer for Flex requires an ArcSDE GDB, so a File GDB was not an option. The two possible hosting sites (University of Redlands or City of Redlands) did not have Linux OS personnel, and they utilize Windows operating systems. SQL Server Express is free with ArcGIS Server Workgroup, and has ArcSDE capabilities. This setup satisfies the client's editing and cost requirements. The user's needs and Information Products Descriptions led to defining the technology used here.

\subsubsection{System Architecture}

The user's needs and IPD's helped define the system architecture in Figure 3-1. 


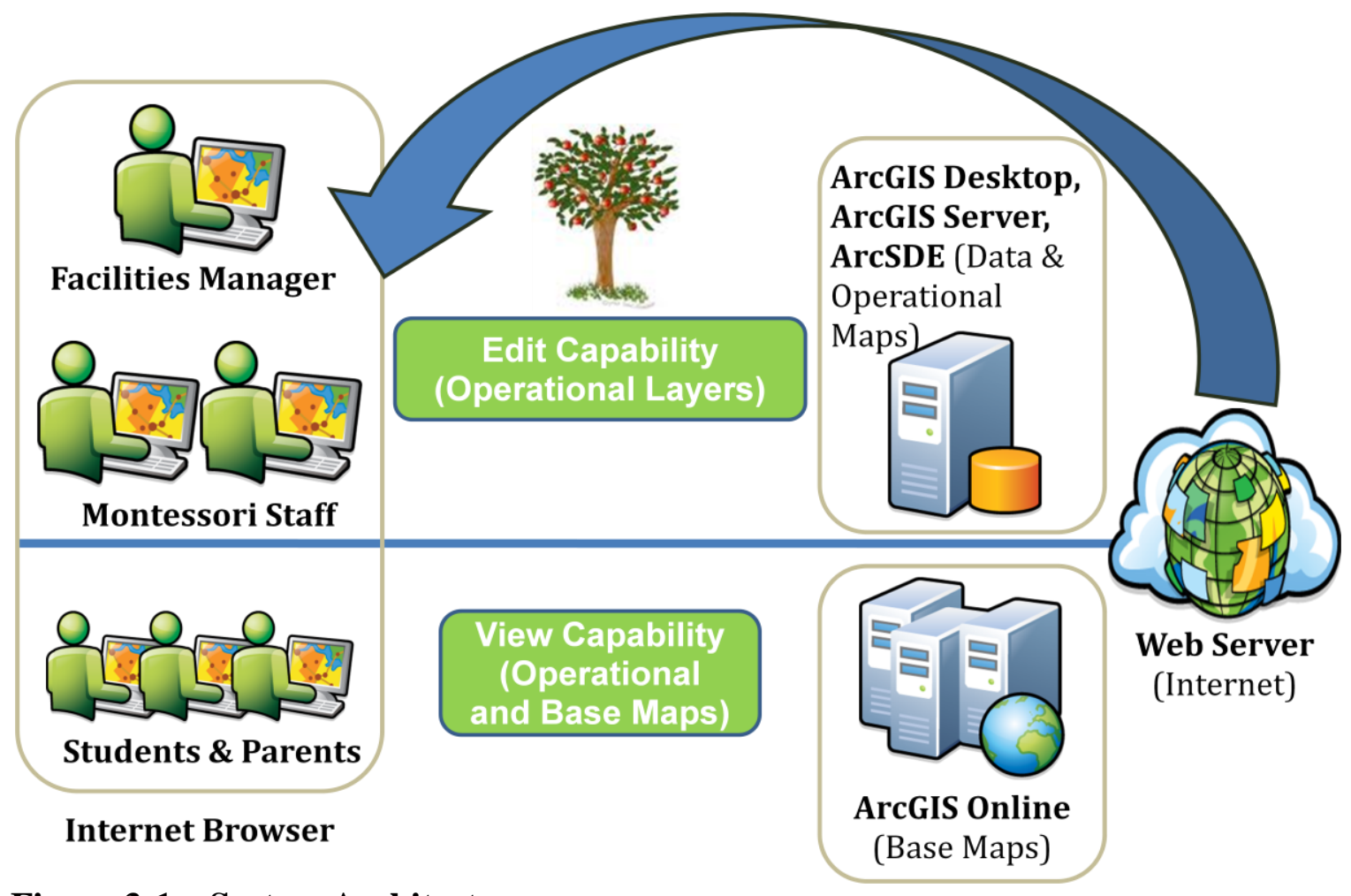

Figure 3-1: System Architecture

The Facilities Manager needs the ability to update the tree types, health, and size of each tree, as well as the ability to add new trees to the system's database via a web browser. This requires extra security to ensure that only certain people have access to update the data. The staff will need edit ability for the transportation participants, as well as the usage data to add the current month's data for electricity, gas, water, and paper. This way they can see the trends of how their Green School Initiative is helping in reducing their ecological footprint. The students and parents will have access to visualize and analyze data, but will not have the ability to edit, unless given access.

ArcGIS online will be used for the satellite imagery, shaded relief, and topological basemaps. The students and staff of Montessori will have view capability of the operational and basemaps over the web, using a simple internet browser.

\subsection{Project Plan}

Figure 3-2 is the initial project plan started in April of 2010. The Work Breakdown Structure shows the major headings of tasks needed within 2010: Requirements Gathering, Develop Project, Deliver the Project, and MIP Development. The arrows between the tasks show dependencies between tasks, as some tasks cannot begin without a completed previous task. Many of the tasks that occurred before April (requirements gathering and data acquisition) completed prior to this project plan. Tasks indicated with a star indicate milestones where client participation and approval were required prior to 


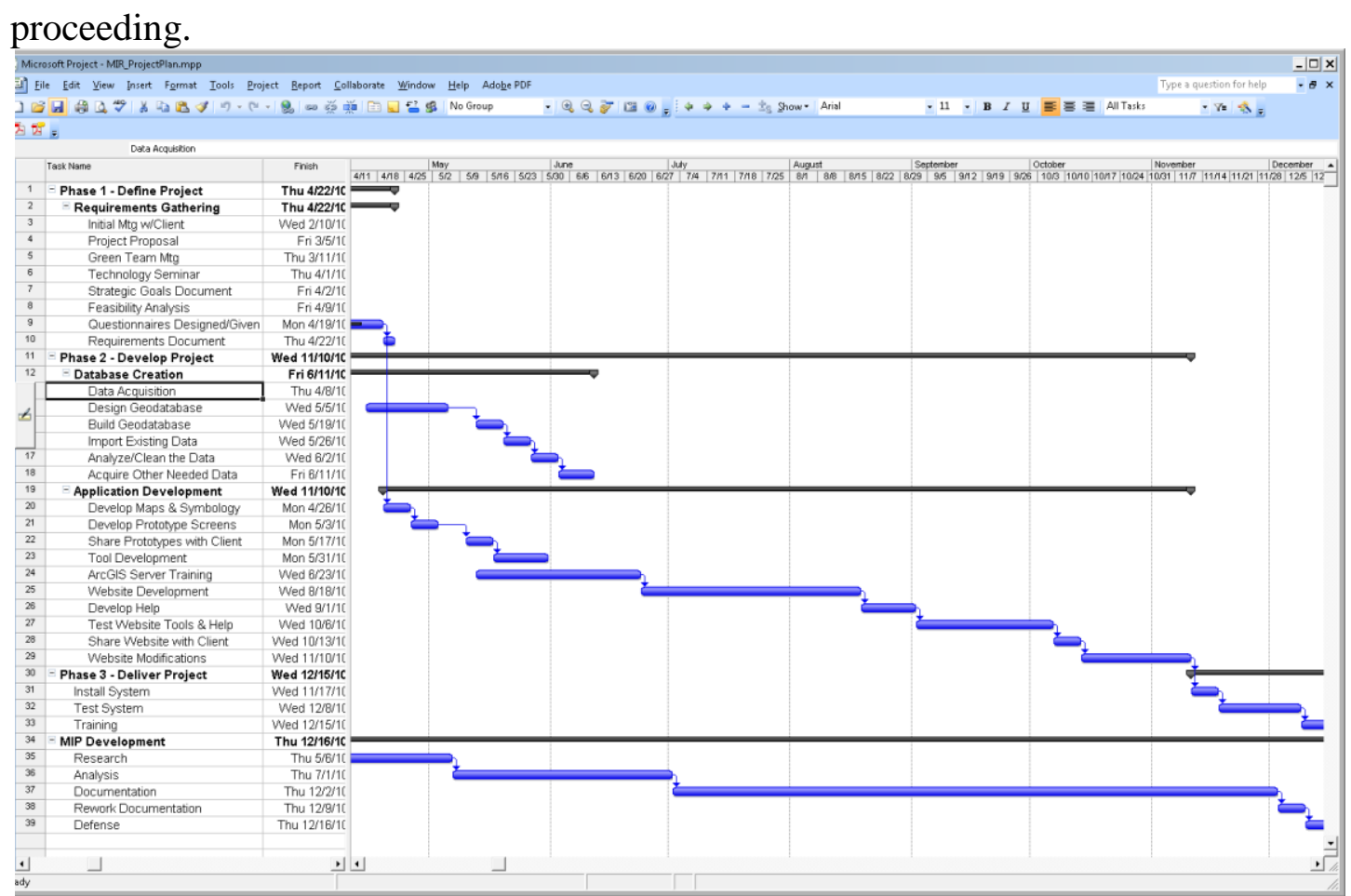

Figure 3-2: Initial Project Plan

The initial project plan became outdated by August. Figure 3-3 has an updated project plan, where many of the updated tasks changed to their accurate start times and duration, many of which were miscalculated. 


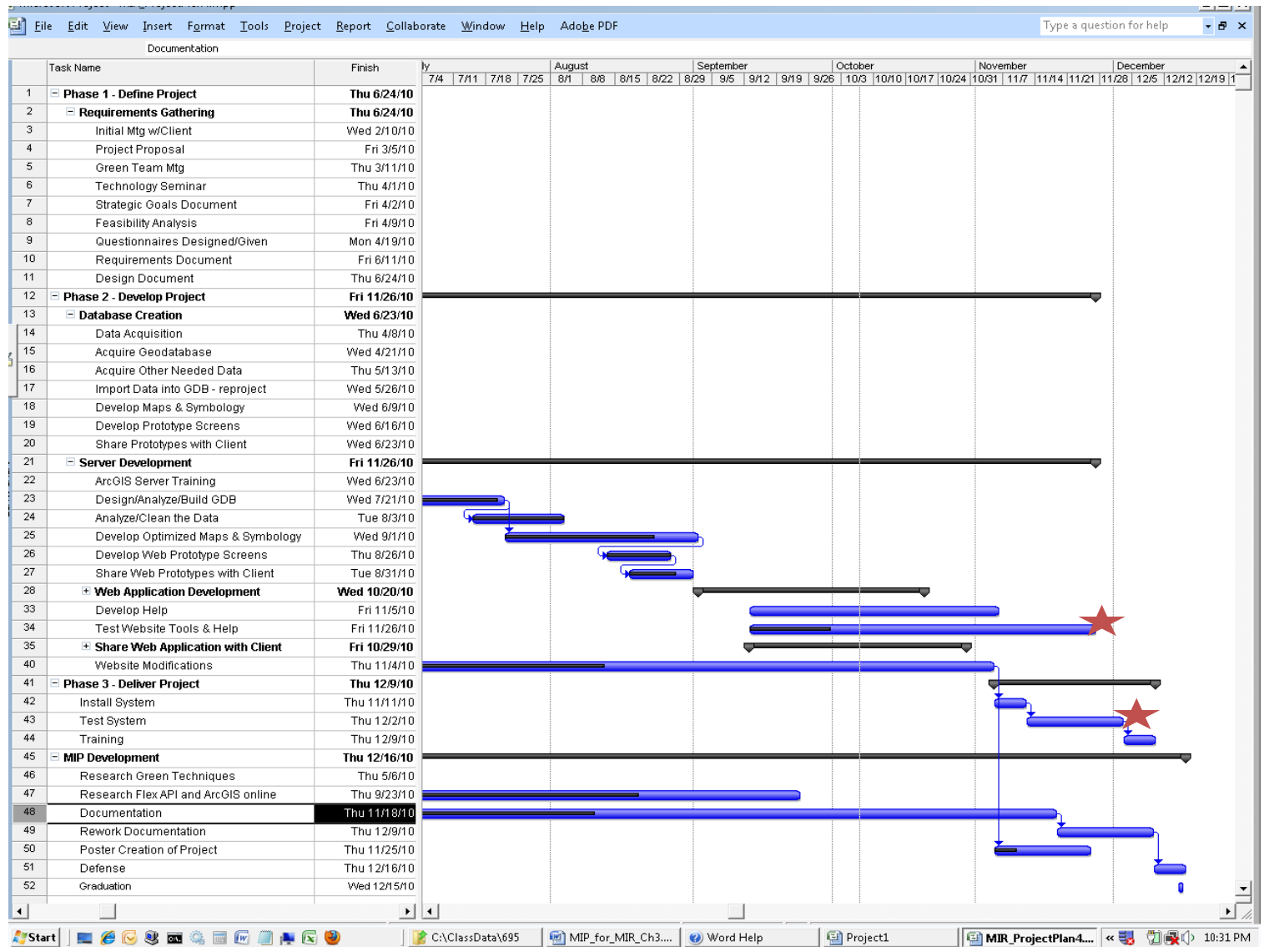

Figure 3-3: Updated Project Plan

\subsection{Summary}

This Mapping Project's design helps implement and track some of the key areas of the Montessori School's Green School Initiative. The client needed a system that combines teaching the students environmental actions with mapping and analysis techniques utilizing a geographic information system. The purpose of this project was to give the staff, students, and parents the ability to visualize and analyze the campus data geographically, helping to discover solutions to resolve their ecological problems. 



\section{Chapter 4 - Database Design}

Every GIS relies on a well-constructed geodatabase (GDB) to store the features and attributes effectively and efficiently. In this chapter, the design of the GDB, defined through the conceptual and logical data models, provides sufficient information to allow a database administrator to create the physical database. The data acquisition, data sources, and methods necessary to prepare it for analysis are below.

\subsection{Conceptual Data Model}

A conceptual data model initiates transforming the client's reality into a data abstraction of entities, characteristics, and their relationships. This conceptualization helps identify any missing or incorrect entities or attributes that are vital to the client's database. Figure 4-1 shows the MIR Campus Map Data Entities.

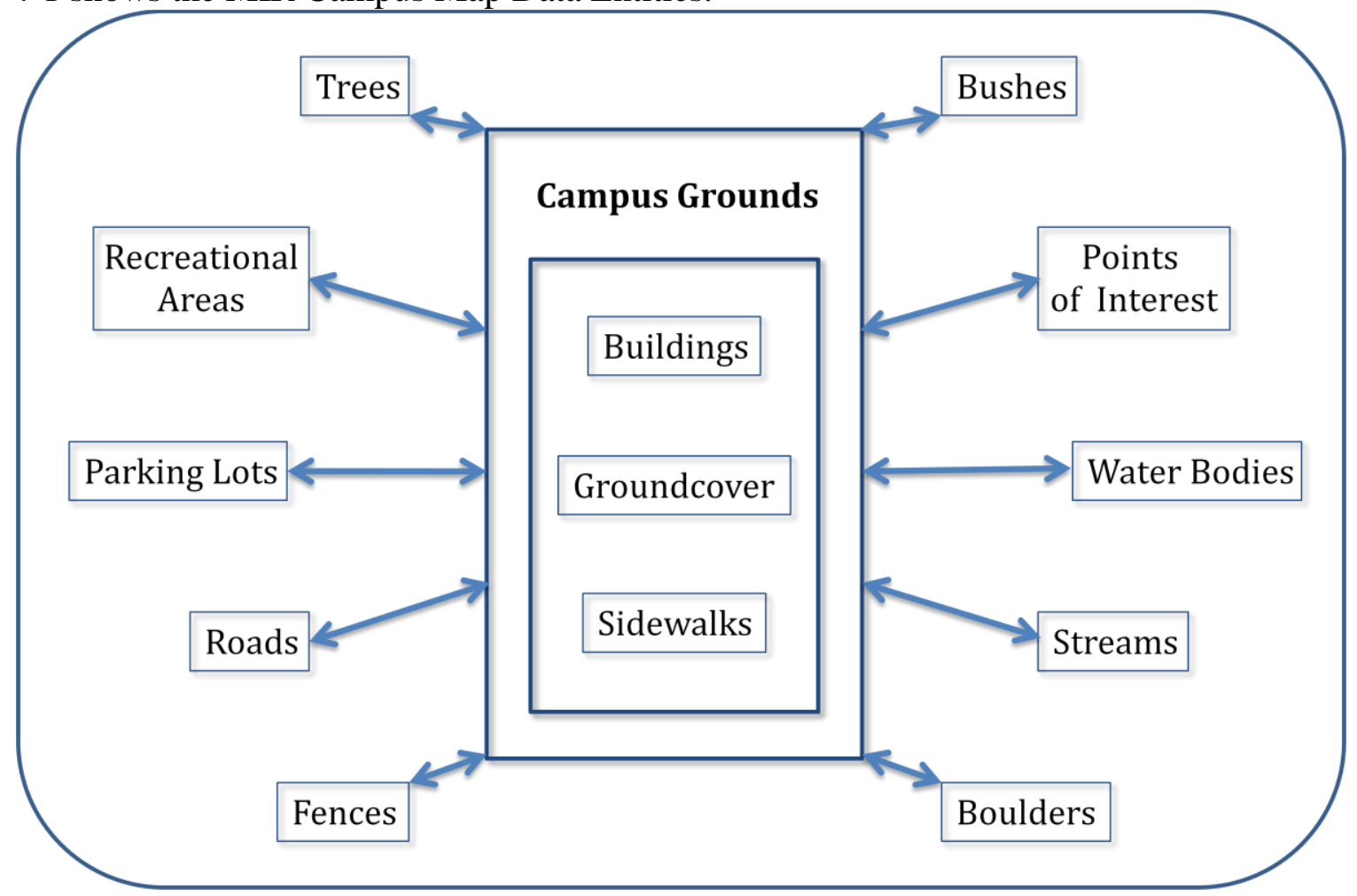

\section{Figure 4-1: Campus Map Data Entities}

Each entity has characteristics or attributes that are associated with it and are stored in the database to describe the entity. Typically, one expresses entities (X) and their characteristics (Y) as "X has Y" statements, as shown in the list below.

1. Trees have a Category, Type, Age, Diameter, Health, Mineral Deficiency, and location associated with them.

2. Recreational Areas have a Name, Type, Shape, and Description.

3. Parking Lots have a Name, Shape, and Type.

4. Roads have a Name, Shape, and Type. 
5. Fences have a Name, Shape, and Type.

6. Bushes have a Type, Shape, and Status.

7. Points of interest have a Name, Type, Shape, and Status.

8. Water Bodies have a Name, Type, and Shape.

9. Streams have a Name, Type, and Shape.

10. Boulders have a Name, Type, and Shape.

11. Buildings have a Name, Type, Address, Owner, and Shape.

12. Groundcover has a Name, Type, and Shape.

13. Sidewalks have a Name, Type, and Shape.

14. Campus Grounds form a Topology with Buildings, Groundcover, and Sidewalks that do not overlap.

15. Carpoolers have a Name, Address, Start, and End Times for school arrival and departure.

16. Bicyclists have a Name, Address, Start, and End Times for school arrival and departure.

When illustrating an Entity - Attribute diagram, shown in Figure 4-2, the entities are in boxes and the attributes are in ovals. Each entity, connected to its attributes via lines extending from the boxes to the ovals, has one or more attribute. Therefore, you can read the diagram as "Carpoolers have a Name, Address, Start, and End Times for school arrival and departure."

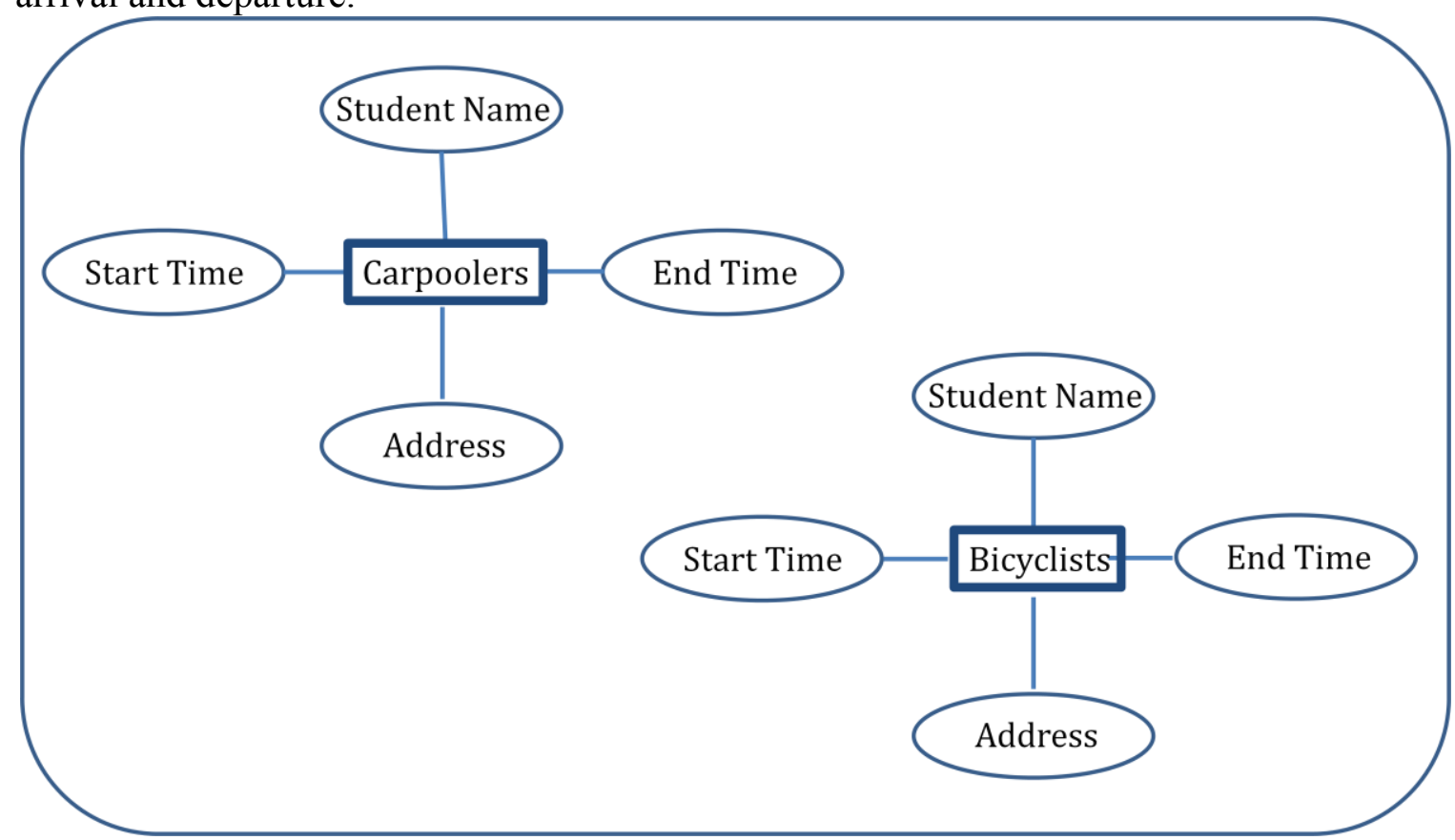

Figure 4-2: Carpool/Safe Bike Bus - Entity Attributes

\subsection{Logical Data Model}

A relational database model is the most common choice to store data in a tabular format because it is conducive to storing spatial and non-spatial data. For this reason, the logical data model consists of the relationship cardinality, feature differentiation, and 
explanatory feature descriptions. The logical schema is a way to model attributes, data types, primary keys, relationships, and how to best store data without duplication. Each feature has an ObjectID, which is useful for differentiation. Most of the cardinality rules are one-to-many $(1: \mathrm{M})$, meaning the campus grounds can have multiple trees, fences, etc. Figure 4-3 shows the campus map features, their attributes, and cardinality rules

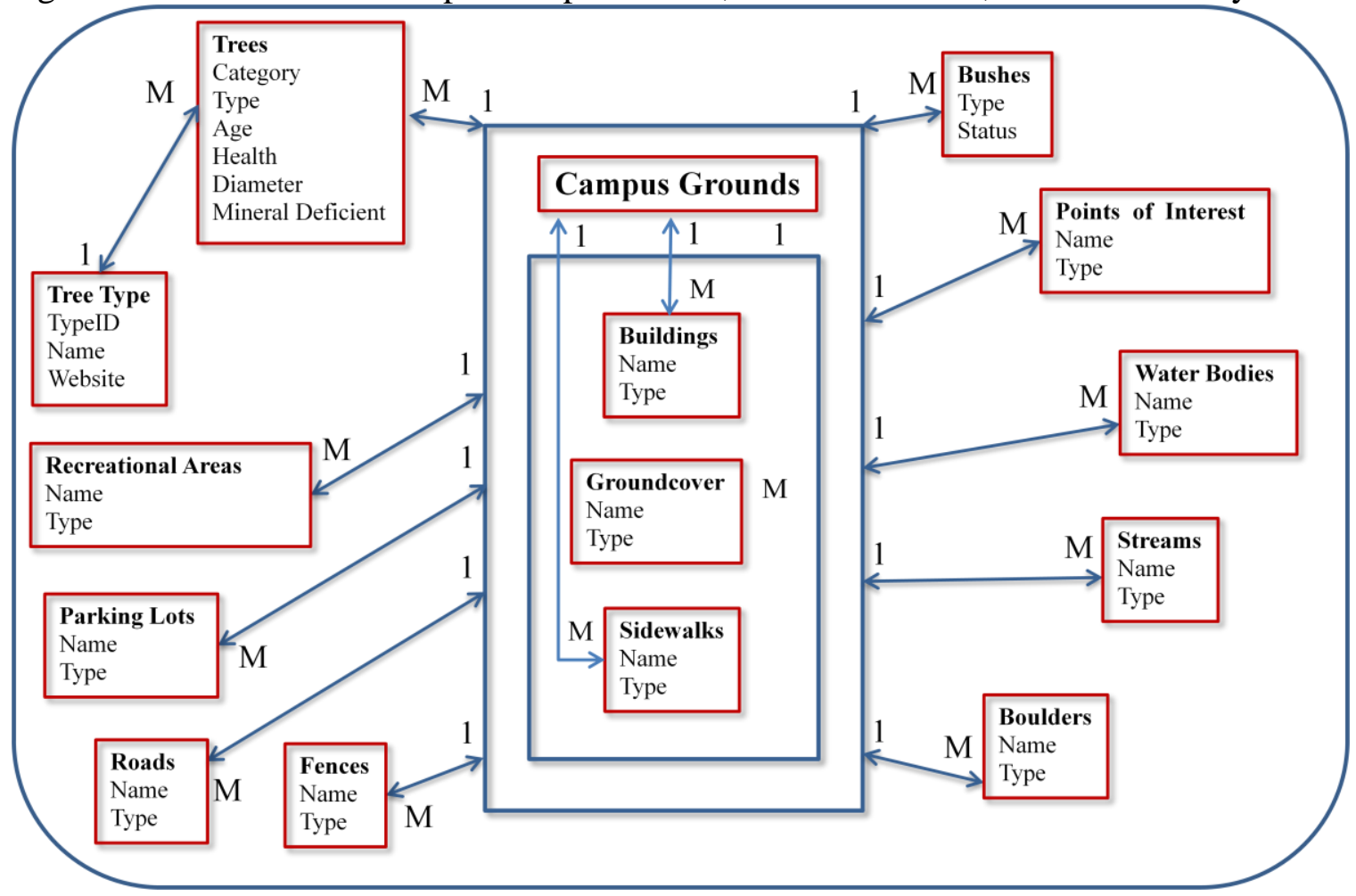

Figure 4-3: Campus Map Entities, Attributes, and Cardinality Rules

Creation of a new tree type table pointing to a website for more information of each tree type eliminates redundancy. Originally, the client wanted a picture of each tree type in the geodatabase, but the raster images did not transfer to the website via the flex viewer, so the implementation of this functionality switched to utilizing attachments. Having a separate tree type table helps conserve space, yet might have a minimal effect on performance, due to the necessary processing time of the relationship class to link the tree and tree type tables together. The Logical Data Model has adequate information for a database administrator to start creating a physical database. The carpool and safe bike bus entities and attributes, shown in Figure 4-4, are separate feature classes. 


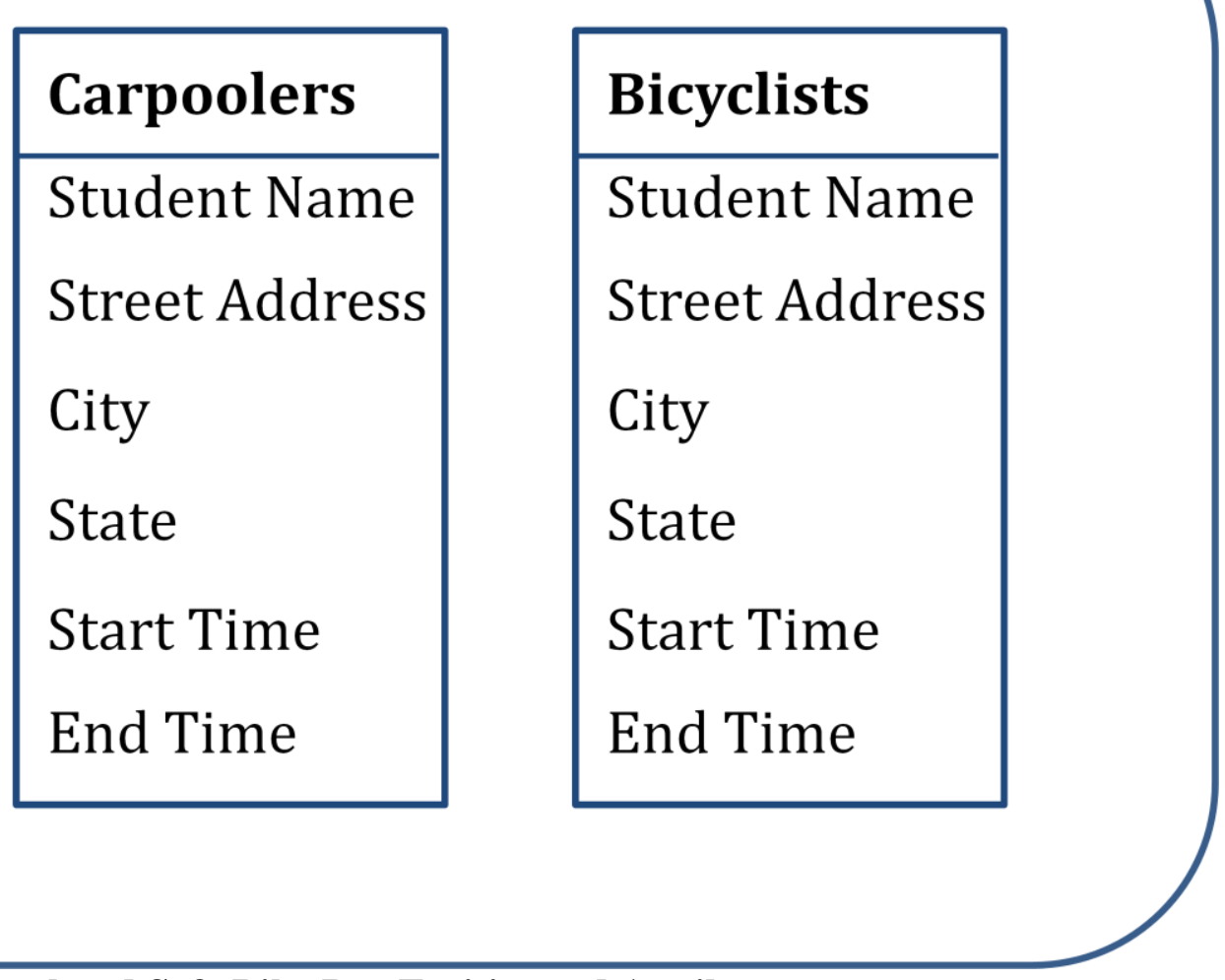

Figure 4-4: Carpool and Safe Bike Bus Entities and Attributes

\subsection{Data Collection Methods}

After collecting the MIR requirements, the data collection method was to find out whom to contact for the data needed. The client provided most of the data, which included the campus, utility, and tree data that make up the campus map, as well as the names and address data that make up the carpool and safe bike bus maps. The City of Redlands provided the Redlands bike route data, as well as the Redlands Institute for the surrounding areas.

\subsection{Data Sources}

Two ESRI employees, who are the parents of Montessori students, helped the students collect the tree data on GIS Day and provided most of the campus data. The students were responsible for collecting the tree attributes (age, type, health, and mineral deficiency) based on paper maps. Greenhouse gas calculation was a Green School Initiative facet, so there was a need to add the diameter attribute to the tree feature class. The campus data was primarily geo-referenced from satellite imagery or gathered from the paper maps. The tree characteristics, entered into a File Geodatabase, needed reprojecting and categorizing for display and editing purposes on the website. 
The Montessori administrators provided the names and addresses of willing participants of carpooling and bicycling to and from school. Existing bike trail data, acquired from the City of Redlands, appears on this map, as well as the Redlands street data from ArcGIS Online. Other bike trail data, acquired from the Redlands Institute, also appears on the map if selected. Since no metadata for these other trails exist, the validity of the "existing" column is not verifiable, so these feature classes will not appear unless the user checks the Redlands Conservancy trails, the Orange Blossom trails, and others under the bicyclists' map selections.

The available utility and usage data for the past two years needed deciphering, as the geographic references were unknown without meter locations to tie to each building. Therefore, the usage data, displayed as graphs, shows the usage over time and tied to each of the features as attachments.

\subsection{Data Refinement and Loading}

Most of the data received was in a different projection, which was good for the City of Redlands, but not for overlaying with the ArcGIS Online Services, which uses the Mercator Auxiliary projection. Most of the data needed re-projecting to the Mercator Auxiliary projection to match up with ArcGIS Online. Editing over the internet was an important requirement to the client, so this would require ArcGIS 10.0 and an ArcSDE geodatabase. To accomplish this, data needed importing into a SQL Server Express geodatabase. Not all of the trees had attributes, as certain students only collected certain characteristics and in certain locations. That is why the tree data appears to be sporadic in the maps. Many of the tree attributes remain as a null in the geodatabase for future collections.

The carpool and safe bike bus data were not complete as some of the students had "nolastname" as a last name. In those cases, their last name was set to null, meaning they would not display on the map.

The utility and usage data were a bit obscure, as some were estimates and not marked clearly. Clarification of the data and identifying meter locations for displaying on the map was not clear, so attaching the graphs created in MS Excel to the features met the usage requirements. In addition, a user can download the attachments, update with future meter readings, and uploaded to the website at any time for current data to display.

\subsection{Summary}

In conclusion, this GIS project relies on a well-constructed geodatabase to model the features and attributes successfully and proficiently on the internet. The requirements of the project led to the design of the geodatabase. The conceptual data model initiated the transformation of the client's current processes into data concepts containing entities, characteristics, and their relationships. The logical data model consists of the relationship cardinality, feature differentiation, and effective feature descriptions, which are useful for modeling attributes, data types, primary keys, relationships, and is how to best store data without duplication. Data acquired from the Montessori School, City of Redlands, and 
the Redlands Institute needed some refining before it could be loaded into the GDB to be useful for the Montessori’s Green School Initiative Mapping Project website. 


\section{Chapter 5 - Implementation}

This chapter describes the implementation and development steps undergone to create a web-based GIS system for the Montessori School. This will assist other GIS professionals or students do the same with similar datasets. The first section is a description of activities needed to create the campus map with editable tree and utility data. The second section is a detailed description of the creation of the carpool, safe bike bus, and local bike trails maps. The third section is a description of activities needed to create the website and user interface (UI) using the ArcGIS Flex Viewer.

\subsection{Campus Map}

The original delivery of the campus data, which consisted of the twenty-six acres of trees, buildings, points of interest, gardens, recreational areas, and parking lots, was a File GDB. In order to have editing capabilities for the system, data needed to reside in an ArcSDE GDB. SQL Server Express was chosen as the ArcSDE database, due to cost (free), size limitations (well under the 2GB limit), and familiarity for the developer. Since the basedata were from ArcGIS Online, the projections had to match up for the data to overlay efficiently without extra projection processing time. Therefore, the ArcGIS Project Tool was used to re-project the feature classes to the Web Mercator Auxiliary projection and stored the new feature classes inside a SQL Server Express GDB.

The next step was bringing the campus data into ArcMap 10.0 and symbolizing the campus entities in bright, colorful, and distinguishable contents for the students to recognize. The campus data consisted of building locations, groundcover, sidewalks, bushes, boulders, gardens, recreational areas, points of interest, and parking lots. The system has attachments for some of the campus entities, providing the ability to upload pictures and documents to share with others for visualization and analysis.

The utility data for electricity, natural gas, water, and paper usage are in Microsoft (MS) Excel and "attach" to the building and groundcover features via the edit widget. These attachments contain the past two years of usage data and graphs. The user can be download the attachments, update them with current data, and then re-attach them to the appropriate building or groundcover locations, as shown in Figure 5-1.
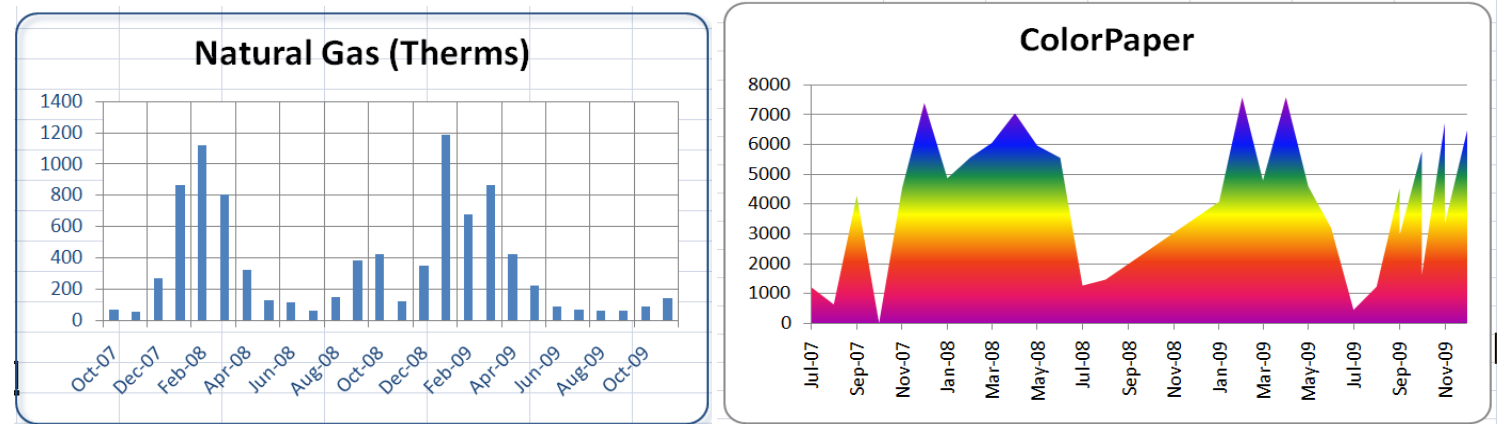

Figure 5-1: Utility and Usage Graph Attachments 


\subsection{Tree Map Service}

A website link for pedagogical purposes for each tree type was required. A new table was created and had the twenty-six different types of trees and websites entered. This allowed for more efficient updating since there were hundreds of trees in the tree table. The websites are accessible through the enhanced search and identify widgets. Classifying the trees into five different categories: evergreen, deciduous, fruit, palm, and grapefruit was a beneficial educational tool. The grapefruit trees had their own category because there were so many of them. Attachments for the tree feature class made pictures and documents available for viewing. Users can add, delete, and move trees, as well as edit their attributes: category, age, diameter, entered date, health, mineral deficiency, source, type, and website, as shown in Figure 5-2.

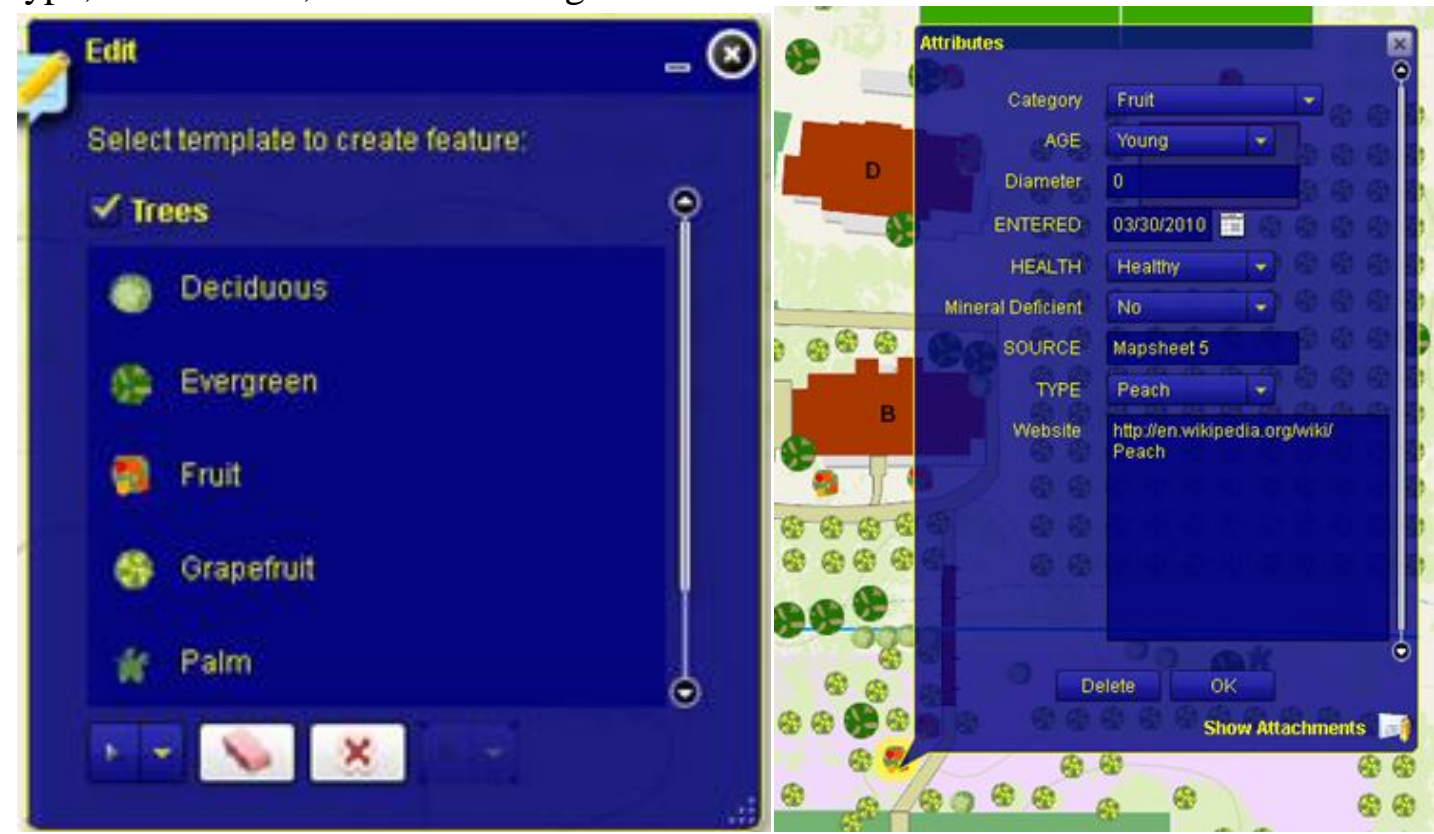

Figure 5-2: Edit Capabilities of the Tree Map Service

Figure 5-3 shows an example of the output of the dynamic legend widget, which illustrates the features that are visible at the current scale of the map shown. 


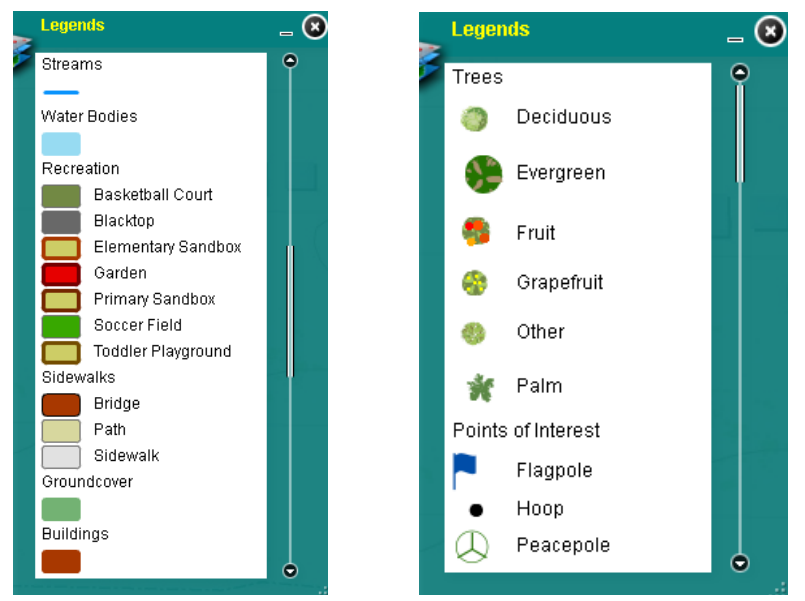

Figure 5-3: Dynamic Legends of the Campus and Tree Map Services

\subsection{Carpool \& Safe Bike Bus Maps}

The carpool and safe bike bus maps each consists of a map to identify other students willing to carpool or ride the safe bike bus (group of students riding bikes together). The addresses of students willing to participate in either the carpool or safe bike bus were provided in MS Excel spreadsheets and needed to be imported into separate feature classes in the GDB. The addresses also needed geocoding to be put onto the campus or safe bike bus maps. Both of the feature classes needed duplicating in ArcMap to be able to distinguish the departure times from the arrival times via symbology. The labels included arrival or departure time as well as the students' names to ensure contact is possible. Due to security reasons, only the initials of the students will be displayed, as well as a color-coded symbol representing time of arrival or departure. Therefore, if a user wanted to find another student to carpool to school with, the user would select the carpool arrival map in the map's drop-down menu, and zoom out to see all available students willing to carpool to school. The user would see their initials, and look for a similar color-coded symbol, representing the same arrival time to school as them. Figure 5-4 represents carpool participant locations, color-coded by arrival time, with their initials shown for contacting purposes in their school registry books. 


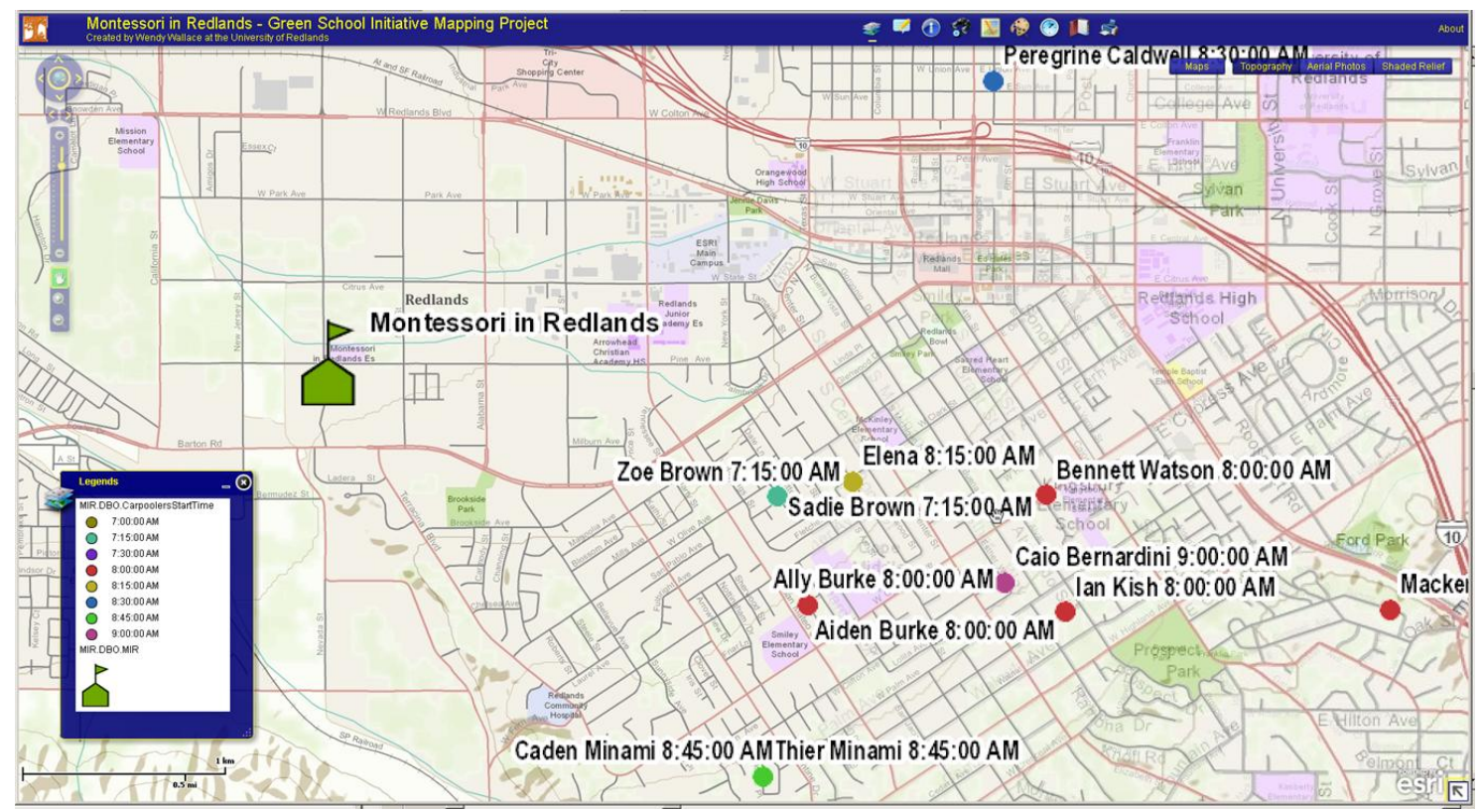

Figure 5-4: Carpool Participants - Arrival Time Map

If a parent or student wanted to carpool and arrive to school at 8:30 am, they would look for other students with that same color-coded arrival time and contact them. A similar process holds true for carpoolers departing from school, and bicyclists arriving to or departing from school. The user just needs to toggle the proper map to display by selecting and un-selecting the right map in the maps drop-down box. The Carpool and Safe Bike Bus maps were changed to only display the initials of the students, with a color-coded dot. Others that might happen upon the website won't be able to decipher the map, but the parents can match up like arrival and departure times, and look up the initials in their student phone book.

The bike trails data, from the City of Redlands, was in a different projection. The Project Tool converted the projection while importing it into the SQL Server Express GDB. A definition query was set to display only presently existing trails. Each type of trail had its own symbol (Class I Bike Path, bike lanes, and off road) to make it easier for the students to see and follow. The Class I Bike Trail, characterized by a thick green line, was the safest route to travel because no cars were close by. Bike lanes were set to a thinner green line. They are still safe, but bicyclists will have to travel alongside cars, as seen in Figure 5-5. 


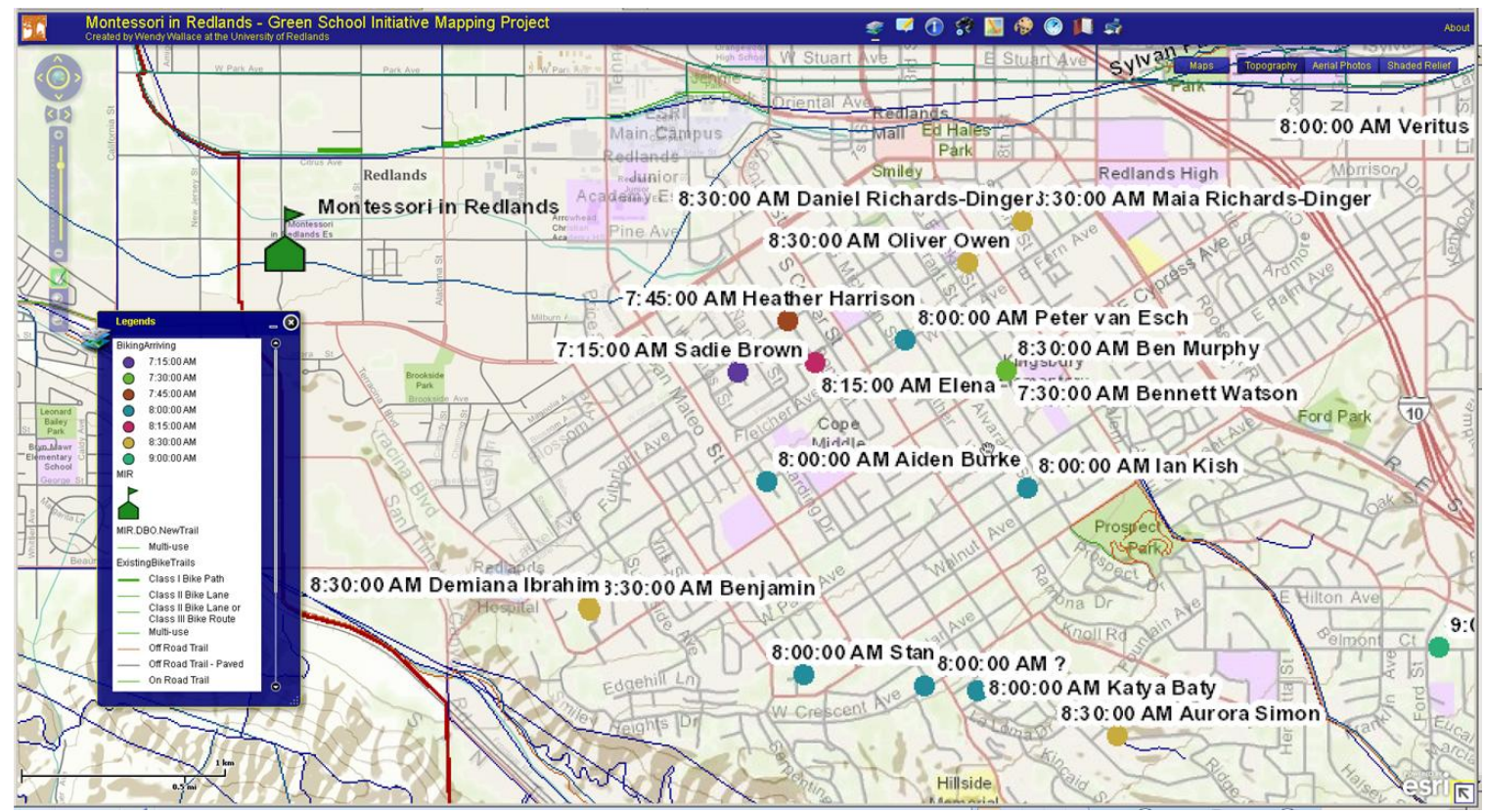

Figure 5-5: Safe Bike Bus Participants and Bike Trails Map

Other bike trail information, gathered from the Redlands Institute GDB, included the Orange Blossom Trail, Nature Conservancy Trails, and others available to see when selected under bicyclists' maps. A user must select these bike trails, as they are not on the map by default. Only the City of Redlands trails are on the map by default.

\subsection{Website Development}

The ArcGIS Flex Viewer was the web development tool of choice to develop the MIR Green School Initiative website. The ArcGIS 10.0 Flex Viewer's editing and attachment functionality were part of the websites capability requirements, but only the Sample Flex Viewer was available during the beginning stages of development. In October of 2010, the ArcGIS Flex Viewer went public and the developer upgraded the MIR website, ArcGIS Desktop, and Server to ArcGIS 10 SP1 to solve some of the anomalies encountered in the early stages of development.

The developer found some enhanced widgets created by the user community on the code sample area of ESRI's Flex Viewer support website. The Enhanced Search widget is capable of searching the tree data by category (i.e. evergreen, fruit), type (i.e. Maple, Apple), size (mature, young), mineral deficient (yes, no), or health (healthy, diseased, dead). Figure 5-6 shows an example of searching the category for fruit trees, with a link to a Wikipedia website for each tree type. 


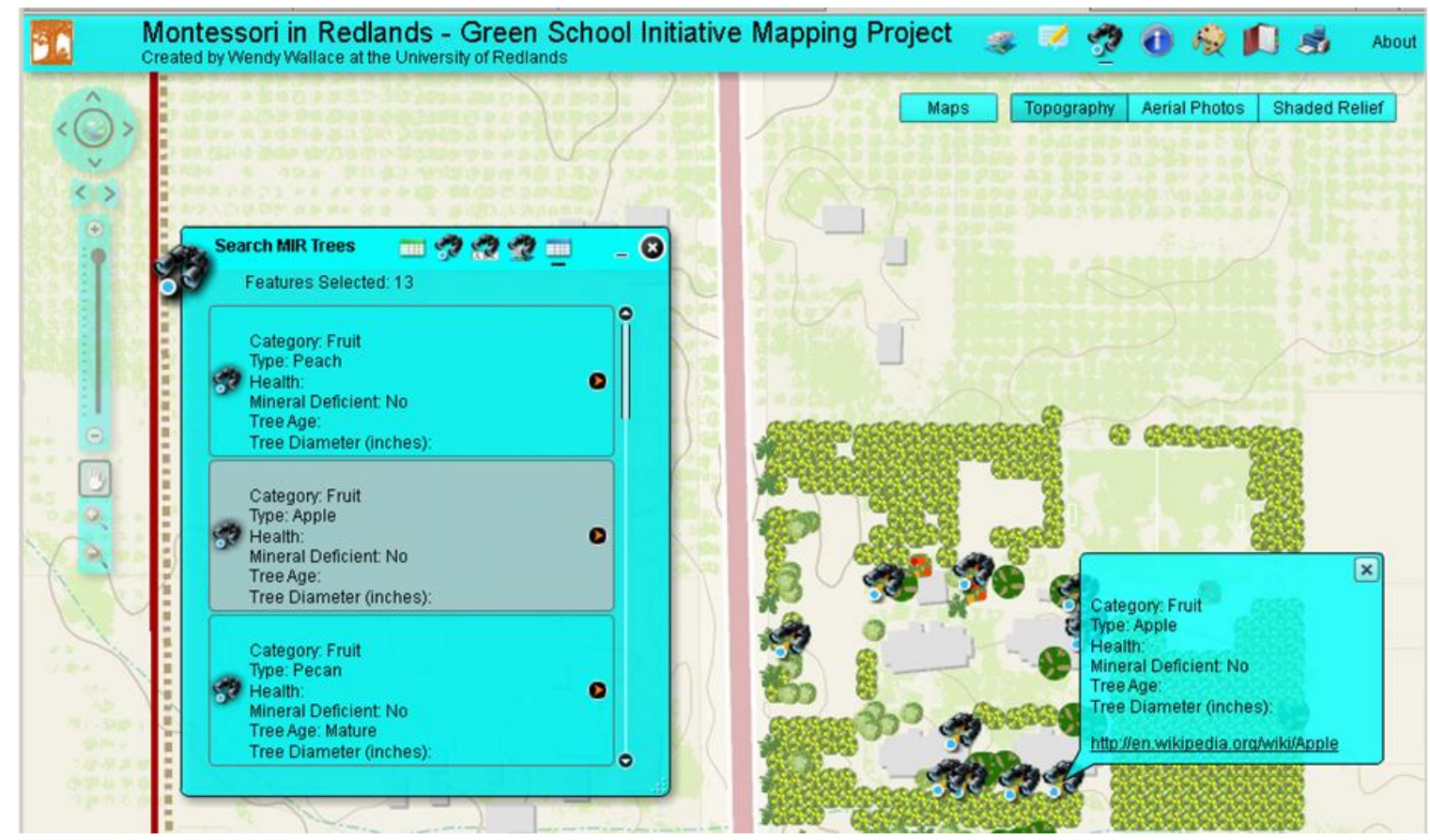

Figure 5-6: Enhanced Search Widget Tied to the Tree Map Service

A user can export the results of the search list to a comma delimited file (.csv), which MS Excel can open, as shown in Figure 5-7.

\begin{tabular}{|c|c|c|c|c|c|c|}
\hline \multicolumn{7}{|c|}{ Search Results } \\
\hline Category & Type & Health & Mineral Deficient & Tree Age & Tree Diameter ( & Website \\
\hline Fruit & Peach & & No & & & http:/ien.wikipedia.org \\
\hline Fruit & Apple & & No & & & http://en.wikipedia.org \\
\hline Fruit & Pecan & & No & Mature & & http:/ien.wikipedia.org \\
\hline Fruit & Apricot & & No & & & http://en.wikipedia.org \\
\hline Fruit & Apple & & No & & & http:i/en.wikipedia.org \\
\hline Fruit & Pear & & No & & & http:i/en.wikipedia.org \\
\hline Fruit & Peach & & No & Young & & http://en.wikipedia.org \\
\hline Fruit & rhorm & & $\mathrm{Nn}$ & Vnuines & & httm-ïnn watlimndia nre \\
\hline
\end{tabular}

Figure 5-7: Exportable Search Results Grid

The upper left corner of Figure 5-6 shows the results of a fruit tree search. The results, shown on the map as binoculars, display in a grid listing pertinent attributes. The user can export this grid to a file to create reports and graphs. 
Figure 5-7 shows an example of the Enhanced Draw and Measure widget, which can draw any size of box, circle, line, or polygon shapes. A user can also append text to the area printed out, save these features to disk, and email them to others. The recipient can load them into this website to see which areas might need addressing.

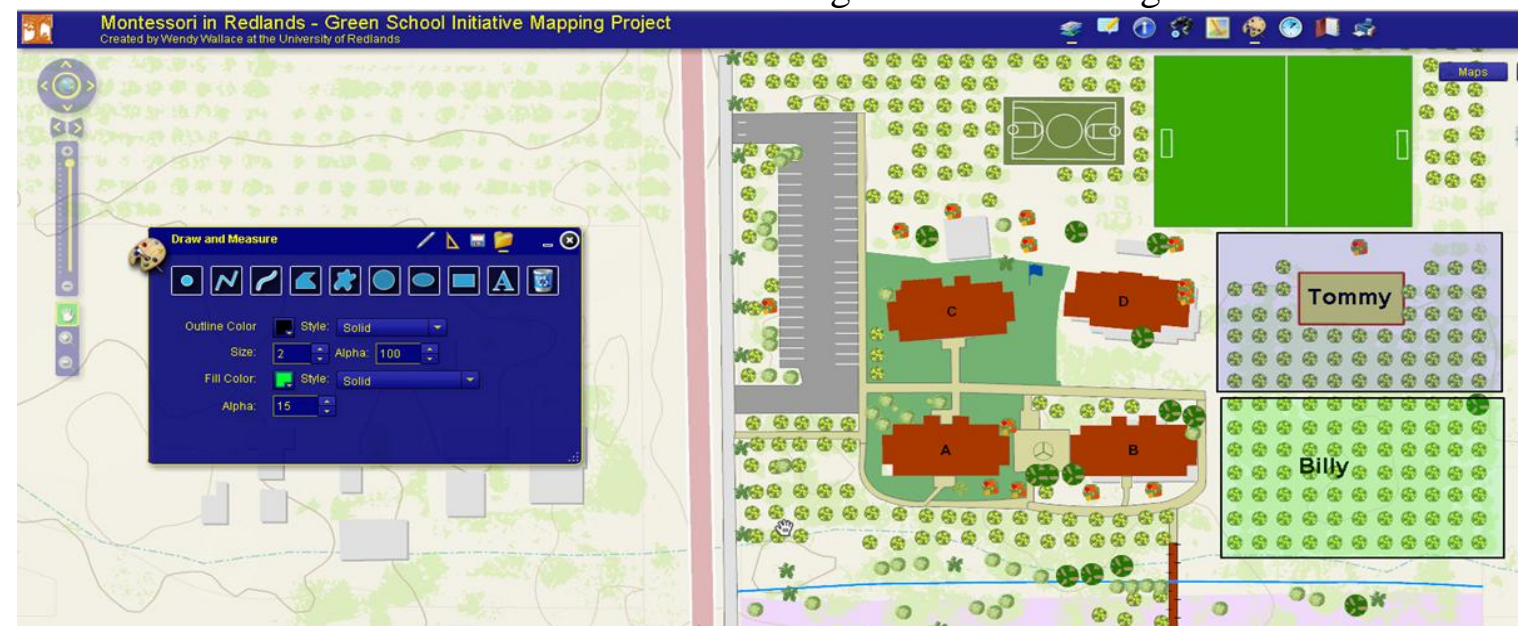

Figure 5-8: Drawing Capabilities from the Draw and Measure Widget

Another feature of the Enhanced Draw and Measure widget is the measuring tool. It automatically measures the length and area of any feature drawn by selecting the checkbox on the measure tab before drawing. In addition, the user can specify the units shown on the website. Figure 5-8 shows an example of the measuring tool, which resides in the Enhanced Draw and Measure widget.

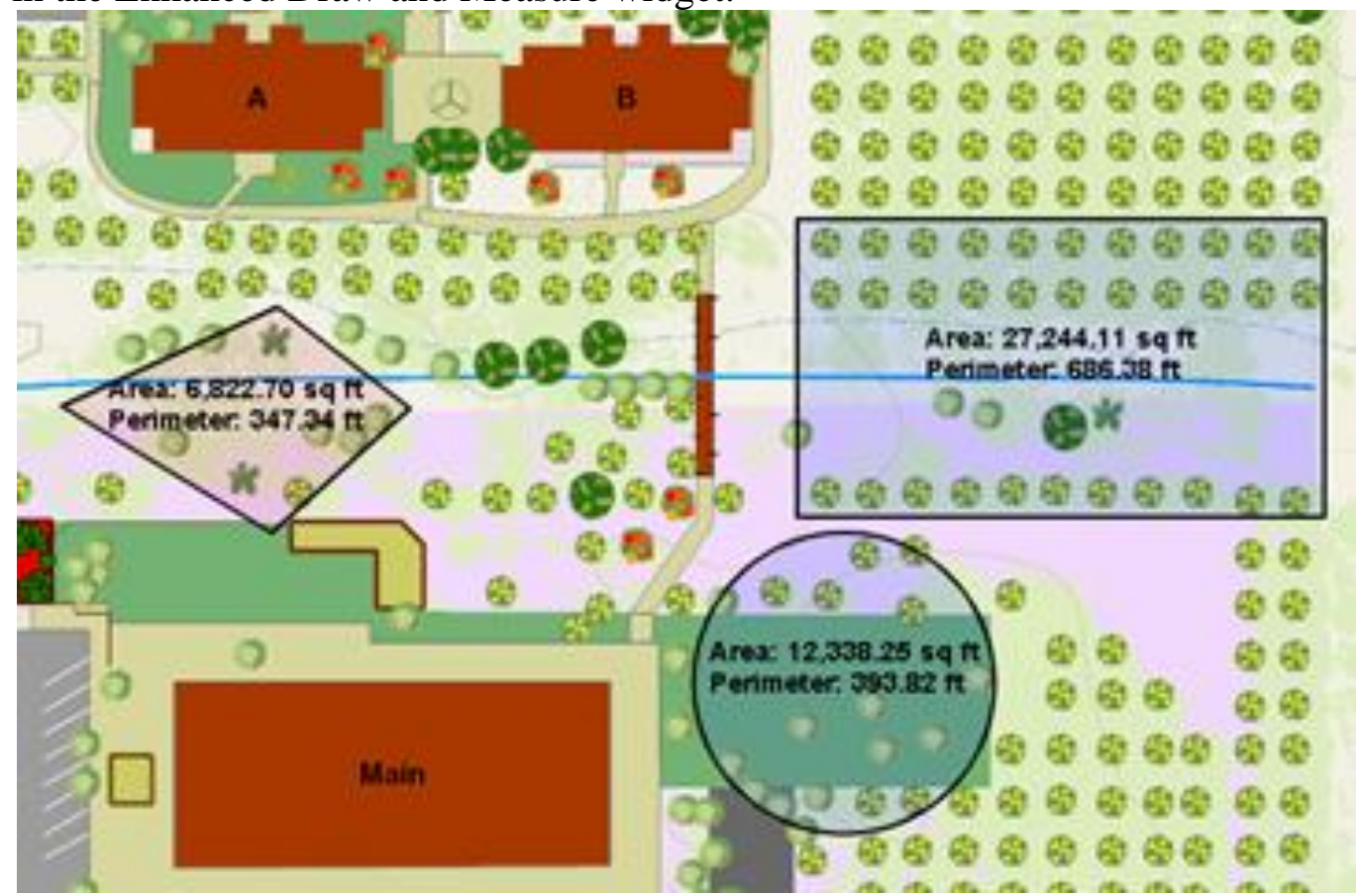

Figure 5-9: Measuring Capabilities from the Draw and Measure Widget 


\subsection{Summary}

In conclusion, the developer divided the implementation of the Montessori Green School Initiative Mapping Project website into separate functions. The most important of these functions was the ability to visualize the school's twenty-six acre campus and the editing capability of its tree characteristics. The administrators of the school like the editing and attachment features that it was incorporated into the students main URL, but they would be editing a test or "playground" version in the database, with a read-only view into the real version of the school maintained by the Facilities Manager. Using the carpool and safe bike bus applications helps pair up likely participants in order to reduce parking lot problems, as well as greenhouse gas emissions. Viewable and editable usage data allows the school to see patterns in the data in terms of time. The primary tools that made the implementation of this website possible were the completion of ESRI's supported ArcGIS Flex Viewer and the Enhanced Identify, Search, and Draw widgets, created and shared by Robert Schreiber, who is part of the ESRI development community. 


\section{Chapter 6 - Results and Analysis}

This chapter is a reflection on the processes used to meet the clients' needs. Specifically, this section identifies what went right as well as what went wrong during the implementation of the mapping project. Many alternative methods were attempted; some did not work, while others identified more efficient or effective directions for this implementation. The developer encountered problems with the campus and tree mapping efforts for the web, the usage graphs, and the web development areas. These are discussed below.

\subsection{Results}

The successful completion of this mapping project resulted from meeting the client's needs. Built a geodatabase to manage data; developed a website with editing capability; produced utility graphs; and created a carpool and safe bike bus application. The ability to edit the tree locations and attributes, via the new ArcGIS Flex Viewer and ArcGIS 10.0 SP1 suite of products, was vital to this project. The utility and usage data went through several iterations, but in the end satisfied the client's requirements by using MS Excel documents as attachments. The carpool and safe bike bus maps served the immediate needs of clearing crowded parking lots and lowering greenhouse gas emissions.

\subsection{Analysis of the Problems Encountered}

\subsubsection{Campus and Tree Map Analysis}

There were hundreds of trees located on campus, and to import pictures of each tree would have been monumental. A tree type table was to provide further tree type information. A raster picture was included in the tree type table. As a proof of concept, the developer imported pictures of trees inside of the database's raster field and Wikipedia's website URL's via ArcMap. The websites turned out to be accessible, but the pictures of the trees did not display on the website. In fact, the raster images caused the edit widget to work incorrectly; the problem was in the amf protocol (default in ArcGIS 10 and the Flex Viewer) for web services. The amf protocol could not handle raster images. When the "SetAMF=False" flag was set in the config.xml file, the protocol used was the JASON protocol. The edit widget started working correctly, yet the raster images still did not appear. The developer deleted the raster field from the GDB and the edit widget worked correctly with the JASON and the original AMF protocol. The developer substituted attachments for the deleted raster field in the GDB, satisfying the client's need for an image of each tree type. After the developer made changes, users can upload their own pictures taken from cell phones and cameras, as well as download existing pictures from the website. 


\subsubsection{Usage Graph Analysis}

The usage graphs caused additional problems, as they did not appear on the website either. The water data had undefined meter numbers and meter types, such as building, non-building, and fire lines. Without knowing which meters connected to which buildings or landscaped areas, the usage data graphs created in ArcMap did not have a map location. Therefore, they did not materialize on the website when served out through ArcGIS Server. The grapefruit groves are self-sufficient, naturally watered via the on-site wells. The utility and paper data were based on the whole campus. Graphs for electricity, natural gas, water, and paper were tied to the main building and groundcover as attachments users can open, edit, and save to the website for other users to see.

\subsubsection{Website Development Analysis}

The ArcGIS Flex Viewer was the preferred web development tool to customize the MIR Green School Initiative website. The Flex API for ArcGIS was difficult to program. The only instructions given regarding programming were sample functional programs without any introduction to the many methods and classes used, or instructions on how to link the samples together. The ArcGIS 10.0 Flex editing and attachment functionality were requirements for this websites' capability.

There were several issues with the Flex Viewer before ArcGIS 10.0 released. Proxy issues hindered the data transferring from the University's Virtual Machines (VMs) to the website. The VM's originally had ArcGIS 9.3.1, which did not have edit capability, but allowed initial development to occur. Other unknown issues would crash the Flex environment with unidentified reasons, but went away after the whole development platform was upgraded to ArcGIS 10.0.

By frequently checking ESRI's Flex Viewer Forums, the developer stayed current on any problems others encountered. Enhanced widgets appeared on ESRI's Flex Viewer Code Sample website, where developers create and share widgets for others to use. The standard ESRI Search widget did not support GDB domains, which is a way for the GDB to restrict users from entering invalid data. Instead, a drop-down menu displays a list of valid values to replace a free-form text-box. The database stores the domains as integers to keep track of the coded values to link it to the actual values. The Enhanced Search widget had much more functionality than the standard search widget, yet it did not handle the GDB domains like the Enhanced Identify widget did. The developer reported this on the Flex Viewer forum, and a few days later the widget reappeared with fixes on the Flex Viewer Code Sample website. The Enhanced Search widget now displayed the domain values, not the integer that is stored in the GDB. The Enhanced Search widget can search the tree data by category (evergreen), type (Maple), size (mature), mineral deficiency, or health. It can also export the result to a comma-delimited file for reports, which was another of the client's requirements.

\subsection{Summary}

In conclusion, when encountering problems during development, the developer remained flexible and tried different tools and methods to accomplish the client's goals and 
objectives. Staying focused on the client's requirements at all times ensured that the project moved forward to the successful completion of a user-friendly interactive website for the Montessori in Redlands School. 



\section{Chapter 7 - Conclusions and Future Work}

The Montessori in Redlands was in need of a tool to help them with their Green School Initiative. By listening to the client's concerns and showing them what GIS could do to help, a list of mutually agreed upon functional and non-functional requirements emerged. Many great ideas came up during the Green School Initiative meetings and were all recorded and considered. Postponing some of the ideas in this project, due to the feasibility analysis and time constraints, are good candidates for future work.

\subsection{Conclusions}

The three main applications the Montessori in Redlands School requested were:

- to visualize, query, and update the twelve acres of tree inventory data

- to find others who would like to carpool or ride the safe bike bus to and from school

- to analyze usage statistics (electricity, gas, water, and paper) over time

The Green School Initiative Mapping Project website meets all three of these requirements, as well as the ability to print maps and reports of their citrus tree data by use of the Enhanced Search tool. Some other interactive and educational tools, such as the Enhanced Draw and Measure tool, categorization of the tree types, and Wikipedia websites meet the school's underlying environmental education requirements for the students.

\subsection{Future Work}

During development, other ideas arose as possible extensions to this project. These ideas were set aside with the clause "if there's time." These ideas are now areas for future work with the Montessori in Redlands School. The staff and students were excited about all of them, but were beyond the scope of this project.

\subsubsection{Biodiversity Project}

The Montessori campus sits upon twenty-six acres, most of which are grapefruit groves. A creek runs through the middle of the school with a bridge over it. This attracts a great amount of wildlife that the students interact with on a daily basis, and they would like to track and monitor animal activity on their campus by uploading pictures and date and timestamp information of bird and animal sightings. Another area of concern is of indigenous plants versus invasive plants. They would like to make this creek habitat more like it used to be in the past, with just native plants to attract and protect the local birds and animals. 


\subsubsection{Mobile Application Project}

The students are eager to learn about GIS and GPS. A mobile application could help the Montessori students collect data in the field, so paper maps would not have to be printed. This would help with one of their environmental concerns of saving paper. They could simply update the GDB directly with a hand-held unit with a custom application for their tree data. The Facilities Manager could also use it for managing campus data, such as fences or landscaping areas that need repairing.

\subsubsection{Archiving Project}

Archiving the data might need to be considered in the future if the utility data is updated regularly. An archiving project would allow the school to examine the usage data patterns over time. Summarizing the older data would require more design work. Students could learn how savings in electricity costs actualized when the school replaced their air conditioning units by comparing energy cost data to the same time the year before. If the school installed solar panels, it would be useful to see the data pre- and post- solar panel days would look like. Archiving the data needs considering because as the usage data grows year to year, it might compromise graph readability. 


\section{Works Cited}

(2006). Retrieved from National Atlas: http://nationalatlas.gov

(2010). Retrieved November 2010, from United States Census Bureau:

http://factfinder.census.gov

Allen, G. (2000). Children's Control of Reference Systems in Spatial Tasks. Foundations of Spatial Cognitive Skill. Spatial Cognition and Computation , 4, pp. 413-429.

Bailey, H., Smaldone, D., Elmes, G., \& Burns, R. (2007). Geointerpretation: The Interpretive Potential of Maps. (C. Ward, Ed.) Journal of Interpretation Research $, 12(2), 45-59$.

Baker, T. R. (2005). Internet-based GIS Mapping in Support of K-12 Education. The Professional Geographer, 57 (1), 44-50.

Bednarz, S. W., \& Audet, R. H. (1999). The Status of GIS Technology in Teacher Preparation Programs. Journal of Geography, 98 (2), 60-67.

Bednarz, S. W., \& van der Schee, J. (2006). Europe and the United States: The Implementation of GIS in Secondary Education in Two Contexts. Technology, Pedagogy and Education , 15 (2), pp. 191-205.

Buck, J. (2002). Retrieved from Go Green Initiative: http://www.gogreeninitiative.org Crampton, J. (2009). Cartography: maps 2.0. Progress in Human Geography, 33, 91100.

Dragicevic, S. (2004). The Potential for Web-based GIS. Journal of Geographic Systems , 6, 79-81. 
Gatrell, J. D. (2001). Structural, Technical, and Definitional Issues: The Case of Geography, GIS, and K-12 Classrooms in the United States. Journal of Educational Technology Systems , 29 (3), 237-249.

Global Warning: Bulletins from a Warmer World. (2004). National Geographic , 206, p. 3.

Globalis - an Interactive World Map. (2006). Retrieved November 2010, from Interactive World Map: http://globalis.gvu.unu.edu/

Green \& Bossomaier, T. (2002). Online GIS and Spatial Metadata. New York, NY: Taylor \& Francis Inc.

Hanke, J. (2007). UC Berkeley Webcasts. Retrieved 10 1, 2010, from UC Berkeley Webcasts - Video and Podcasts: http://webcast.berkeley.edu/event_details.php?webcastid=21135

Holt, J. L. (2010). The Earth Is Our Home - Children Caring for the Environment.

Johnson, H. D. (1995). Green Plans, Greenprint for Sustainability. University of Nebraska Press.

Keiper, T. A. (1999). GIS for Elementary Students: An Inquiry into an Approach to Learnning Geography. Journal of Geography, 98 (2), 47-59.

Kerski, J. (2001). A National Assessment of GIS in American High Schools. International Research in Geographical and Environmental Education, 10, $72-$ 87.

Kerski, J. J. (2003). The Implementation and Effectiveness of Geographic Information Systems Technology and Methods in Secondary Education. Journal of Geography , 102, 128-137. 
King, H. (2006). Understanding Spatial Literacy: Cognitive and Curriculum Perspectives. Planet , 17, 26-28.

Kraak, M.-J. (2004). The Role of the Map in a Web-GIS Environment. Journal of Geography, 83-93.

Ludwig, R. A. (2000). GIS in Schools. Redlands: ESRI Press.

MacEachren. (1994). Visualization in Modern Cartography: Setting the Agenda. Visualization in Modern Cartography, 2, 1-12.

Milson, A. J. (2005). GIS in K-12 Education: Pedagogical Tool or Weapon of Mass Distraction? Research in Geographic Education, 7 (1), $62-73$.

Milson, A. J. (2006). Local Data, Global Concepts: GIS Internet Mapping. The Geography Teacher , 3 (1), 14-16.

Moore, D. (2004). Retrieved from Green Schools: http://www.greenschools.net/ Murphy, E. (2008). Montessori's Green School Initiative. Retrieved from Montessori's Green School Initiative: https://my.pbworks.com

NRC. (2006). Learning to Think Spatially. Washington D.C.: National Academies Press.

Organ, R. (2008). Retrieved October 2010, from Project Green School: http://www.ProjectGreenSchool.org

Palladino, S. (1994). A Role for Geographic Information Systems in the Secondary Schools: An Assessment of the Current and Future Possibilities. MS Thesis. University of California, Santa Barbara.

Peuquet, D. (2002). Representations os Space and Time. New York: Guilford Press. Poulit, J. (2007). Connecting People while Preserving the Planet - Essays on Sustainable. Redlands: ESRI Press. 
Purcell, A. D., Pomomarenko, A. L., \& Brown, S. C. (2006). A Fifth Grader's Guide to the World. Science and Children, 43 (8).

Roblyer, M. (2006). Integrating Educational technology into Teaching (Fourth ed.). New Jersey: Pearson Education.

Sobel, D. (1998). MapMaking with Children - Sense of Place for the Elementary Years. Portsmouth, NH: Heinemann.

Stone, M.K./ Center for Ecoliteracy. (2009). Smart By Nature - Schooling for Sustainability. Healdsburg, Ca: Watershed Media.

Wiegand, P. (2006). Learning and Teaching with Maps. New York, NY: Routledge. 